ARTICLE

https://doi.org/10.1038/s41467-019-09114-z

\title{
Amyloid $\beta$ oligomers suppress excitatory transmitter release via presynaptic depletion of phosphatidylinositol-4,5-bisphosphate
}

Yang $\mathrm{He}^{1}$, Mengdi Wei ${ }^{1}$, Yan Wu${ }^{1}$, Huaping Qin ${ }^{1}$, Weinan $\mathrm{Li}^{1}$, Xiaolin Ma1, Jingjing Cheng${ }^{1}$, Jinshuai Ren', Ye Shen ${ }^{1}$, Zhong Chen², Binggui Sun (10 ${ }^{1}$, Fu-De Huang ${ }^{3}$, Yi Shen (D) ${ }^{1} \&$ Yu-Dong Zhou (D) ${ }^{1}$

Amyloid $\beta$ ( $A \beta$ ) oligomer-induced aberrant neurotransmitter release is proposed to be a crucial early event leading to synapse dysfunction in Alzheimer's disease (AD). In the present study, we report that the release probability $(\mathrm{Pr})$ at the synapse between the Schaffer collateral (SC) and CA1 pyramidal neurons is significantly reduced at an early stage in mouse models of $A D$ with elevated $A \beta$ production. High nanomolar synthetic oligomeric $A \beta_{42}$ also suppresses $\operatorname{Pr}$ at the SC-CA1 synapse in wild-type mice. This $A \beta$-induced suppression of $\operatorname{Pr}$ is mainly due to an mGluR5-mediated depletion of phosphatidylinositol-4,5-bisphosphate $\left(P I P_{2}\right)$ in axons. Selectively inhibiting $A \beta$-induced $\mathrm{PIP}_{2}$ hydrolysis in the $C A 3$ region of the hippocampus strongly prevents oligomeric $A \beta$-induced suppression of $\operatorname{Pr}$ at the SC-CA1 synapse and rescues synaptic and spatial learning and memory deficits in APP/PS1 mice. These results first reveal the presynaptic mGluR5-PIP 2 pathway whereby oligomeric $A \beta$ induces early synaptic deficits in AD.

\footnotetext{
${ }^{1}$ Department of Neurobiology, and Department of Ophthalmology of the First Affiliated Hospital, NHC and CAMS Key Laboratory of Medical Neurobiology, Zhejiang University School of Medicine, Hangzhou 310058, China. ${ }^{2}$ Department of Pharmacology, NHC and CAMS Key Laboratory of Medical Neurobiology, College of Pharmaceutical Sciences, Zhejiang University, Hangzhou, Zhejiang 310058, China. ${ }^{3}$ Center for Stem Cell and NanoMedicine, Laboratory for System Biology, Shanghai Advanced Research Institute, Chinese Academy of Sciences, Shanghai 201210, China. These authors contributed equally: Yang He, Mengdi Wei. Correspondence and requests for materials should be addressed to F.-D.H. (email: huangfd@sari.ac.cn) or to Y.S. (email: yshen2@zju.edu.cn) or to Y.-D.Z. (email: yudongzhou@zju.edu.cn)
} 
T he neuropathology of Alzheimer's disease (AD) is characterized by occurrence of senile plaques containing amyloid $\beta(\mathrm{A} \beta)$ aggregates and neurofibrillary tangles formed by hyperphosphorylated tau in the brain ${ }^{1-3}$. An important cellular correlate of cognitive decline in $\mathrm{AD}$ is synapse loss ${ }^{4,5}$. Thus, many studies in $\mathrm{AD}$ focus on exploring the underlying mechanisms of neurotoxic effects of $A \beta$ and hyperphosphorylated tau on synapse loss and neuronal death ${ }^{6}$. However, synaptic dysfunction may occur before synapse loss in early $\mathrm{AD}^{4}$. Therefore, elucidating how pathogenic $A \beta$ and tau species alter synaptic transmission is crucial to the diagnosis and treatment of AD. In recent years, investigating how $A \beta$ modulates synapse function in early $\mathrm{AD}$ has attracted great attention ${ }^{7,8}$. The neurotoxic soluble $A \beta$ oligomers, including the most toxic oligomeric $A \beta_{42}$, have been shown to alter synaptic plasticity and synaptic transmission in various $\mathrm{AD}$ animal models via a variety of synaptic targets of $A \beta$ such as ionic neurotransmitter receptors, $G$ protein-coupled receptors (GPCRs), receptor tyrosine kinases, and cellular prion proteins $\left(\operatorname{Pr} P^{C}\right)^{9,10}$. Although many of these $A \beta$ targets exist in both presynaptic and postsynaptic $\operatorname{loci}^{11}$, and $A \beta$ oligomers accumulate at both sides of the excitatory synapse ${ }^{12,13}$, majority of the studies have only examined the toxic gain of function for $\mathrm{A} \beta$ as a result of its interaction with the postsynaptic targets ${ }^{14,15}$. Examinations of $A \beta$-induced abnormalities in synaptic transmission have nevertheless revealed presynaptic defects are often more prominent than postsynaptic abnormalities ${ }^{16,17}$. Thus, it is pivotal to unravel the presynaptic targets of $A \beta$ in $A D$.

Physiological concentration of $A \beta$ (picomolar) ${ }^{18}$ has been shown to positively regulate synaptic transmission via upregulating the presynaptic neurotransmitter release probability $(\mathrm{Pr})^{19}$. Low to moderate levels of $A \beta$ may augment $\operatorname{Pr}$ via increasing presynaptic $\mathrm{Ca}^{2+}$ by promoting presynaptic amyloid precursor protein (APP) homodimerization ${ }^{20}$, activating exocytotic $\mathrm{Ca}^{2+}$ channel ${ }^{21}$, and regulating presynaptic $\alpha 7$ nicotinic acetylcholine receptors 22,23 . However, how pathological level of oligomeric $\mathrm{A} \beta$ (nanomolar) ${ }^{18}$ leads to presynaptic defects remains largely obscure. Controversial results exist in the literature showing pathogenic $A \beta$ may exert negative $e^{16,17,24-26}$, positive ${ }^{27,28}$, or $\mathrm{no}^{29,30}$ effects on neurotransmitter release. Different $A \beta$ species and their targets, various assemblies of $A \beta$ monomers, and duration of $A \beta$ action may account for these disparate observations ${ }^{9}$. Furthermore, there is little evidence of what the presynaptic targets of pathogenic $\mathrm{A} \beta$ are in early $\mathrm{AD}$. There are contradicting results with respect to how nanomolar $A \beta$ oligomers regulate voltage-gated $\mathrm{Ca}^{2+}$ channels ${ }^{25,27,31}$ and SNARE complex proteins ${ }^{26,28}$ to disrupt presynaptic neurotransmitter release.

In the current study, we aim to clarify the presynaptic deficit at an excitatory hippocampal synapse in $\mathrm{AD}$ models and determine the presynaptic target of pathological level of oligomeric $A \beta_{42}$. We identified a nanomolar oligomeric $A \beta_{42}$-induced, presynaptic metabotropic glutamate receptor 5 (mGluR5)-mediated hydrolysis of membrane phosphatidylinositol-4,5-bisphosphate $\left(\mathrm{PIP}_{2}\right)$ underlies the diminished $\mathrm{Pr}$ in early AD. Postsynaptic mGluR5 has been shown to function as an $A \beta$ receptor or co-receptor with $\mathrm{PrP}^{\mathrm{C} 32-34}$ and blocking mGluR5 reduces cognitive impairment in $\mathrm{AD}$ mouse model ${ }^{35-37}$. Oligomeric $\mathrm{A} \beta^{38}$ and apolipoprotein $\mathrm{E} 4^{39}$ are also known to interfere with $\mathrm{PIP}_{2}$ metabolism and reduction of $\mathrm{PIP}_{2}$ phosphatase synaptojanin 1 ameliorates synaptic and behavioral deficits in $\mathrm{AD}^{40}$. Our results for the first time establish that increasing the presynaptic $\mathrm{PIP}_{2}$ level is an effective way to improve cognition in $\mathrm{AD}$.

\section{Results}

Reduced transmission in early AD involves a reduction in $\mathrm{Pr}$. To determine the synaptic deficits in early $\mathrm{AD}$, we first examined spine morphology and density of apical dendrites in CA1 pyramidal neurons in 6-7-month-old APP (Swe); PS1( $\triangle \mathrm{E} 9)$ (APP/PS1) mice (Fig. 1a-c). We compared the total spine density (Fig. 1c) and the density of filopodium-like, thin, stubby, and mushroom-shaped spines (Fig. 1b) in wild-type (WT) and APP/PS1 mice. We found that in APP/PS1 mice, there were no changes in the total spine density and the density of mature forms of spines in comparison to WT mice, although the filopodium-like spine density was significantly increased. The result is consistent with a previous study showing spine loss did not occur in CA1 stratum radiatum in APP/ PS1 mice, whereas the number of small-headed spines was significantly increased ${ }^{41}$. We next recorded miniature excitatory postsynaptic currents (mEPSCs) in CA1 pyramidal neurons in 6-7month-old WT and APP/PS1 mice (Fig. 1d, e). The frequency but not the amplitude of mEPSCs was significantly lower in APP/PS1 mice than in WT controls. We then recorded evoked EPSCs at the Shaffer collateral (SC) to CA1 pyramidal neuron (SC-CA1) synapse and found that the amplitude of SC-CA1 EPSCs was strongly decreased in 6-7-month-old APP/PS1 mice (Fig. 1f, g). These changes in mEPSC frequency and SC-CA1 EPSC amplitude were not observed in 4-month-old APP/PS1 mice (Supplementary Fig. 1), suggesting that the synaptic transmission deficits occur at a later stage when $A \beta$ production is greatly elevated (Supplementary Fig. 2). Indeed, in 4-month-old APP (Swe/Flo/Lon); PS1 (M146L/L286V) mice $(5 \mathrm{xFAD})$ with an accelerated $\mathrm{A} \beta$ production (Supplementary Fig. 2), the frequency of mEPSCs in CAl neurons and the amplitude of SC-CA1 EPSCs were greatly reduced in comparison to APP/PS1 and WT mice of the same age (Supplementary Fig. 1a-d). By contrast, 6-7-month-old PS1 ${ }^{\mathrm{M} 146 \mathrm{~V}}$ knock-in mice (M146V) with a low $A \beta$ production exhibited slightly decreased mEPSC frequency and amplitude compared to their WT littermates (Supplementary Fig. 1e, f). Interestingly, SC-CA1 EPSCs were smaller in M146V than in control mice at 6-7-month of age, implying that an $A \beta$ independent mechanism may underlie the decreased synaptic transmission. These results suggest that decreased synaptic transmission in the hippocampus may be a hallmark in $\mathrm{AD}$ mouse models that show a high level of $A \beta$ accumulation.

To further test if the reduced hippocampal synaptic transmission in $\mathrm{AD}$ mouse models is dependent on $\mathrm{A} \beta$ levels, we first bath applied synthetic oligomeric $A \beta_{42}$ at various concentrations in brain slices from WT mice. We observed that bath application of $400 \mathrm{nM}$ oligomeric $\mathrm{A} \beta_{42}$ for 20 min induced a significant decrease in the amplitude of SC-CA1 EPSCs, whereas $20 \mathrm{nM}$ and $100 \mathrm{nM}$ oligomeric $A \beta_{42}$ respectively exerted positive and no effects on the evoked responses (Supplementary Fig. 3). Four hundred nanometers of $\mathrm{A} \beta_{42}$ fibrils, on the other hand, did not alter the amplitude of SC-CA1 EPSCs (Supplementary Fig. 3). We thus chose $400 \mathrm{nM} \mathrm{A} \beta_{42}$ oligomers for further in vitro studies. Bath application of $400 \mathrm{nM}$ oligomeric $A \beta_{42}$ for 20 min reduced both mEPSC amplitude and frequency in CA1 pyramidal neurons (Fig. 1h, i) and suppressed SC-CA1 EPSC amplitude (Fig. 1j, k) in WT mice. Interestingly, $400 \mathrm{nM}$ oligomeric $\mathrm{A} \beta_{42}$ induced a greater suppression of mEPSCs in frequency than in amplitude (Fig. 1e), suggesting that the site of action of oligomeric $A \beta_{42}$ was mainly presynaptic. These data indicate that $400 \mathrm{nM}$ oligomeric $A \beta_{42}$ exerts similar effect on hippocampal synaptic transmission as in $\mathrm{AD}$ mouse models with a high level of $\mathrm{A} \beta$ accumulation.

Although there was no spine loss in 6-7-month-old APP/PS1 mice, $A \beta$-induced reduction of the number of active boutons may account for the decreased mEPSC frequency in these animals, as nanomolar $A \beta$ oligomers can reduce the recycling pool and increase the resting pool of synaptic vesicles ${ }^{42}$. To test this hypothesis, we loaded active synaptic vesicles with FM1-43 in cultured hippocampal neurons. Compared to vehicle treatment, treatment with $400 \mathrm{nM}$ oligomeric $A \beta_{42}$ did not change the number of active boutons in hippocampal neurons (Fig. 1l, m). These results indicate that $A \beta$-induced inhibition of mEPSC 

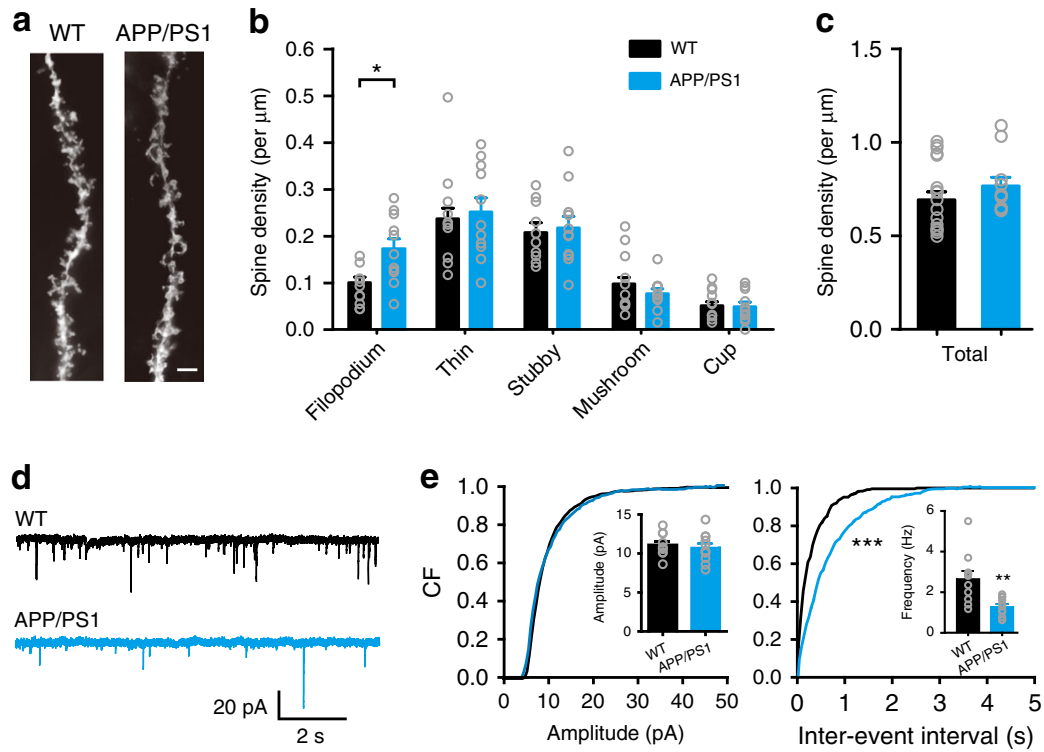

f
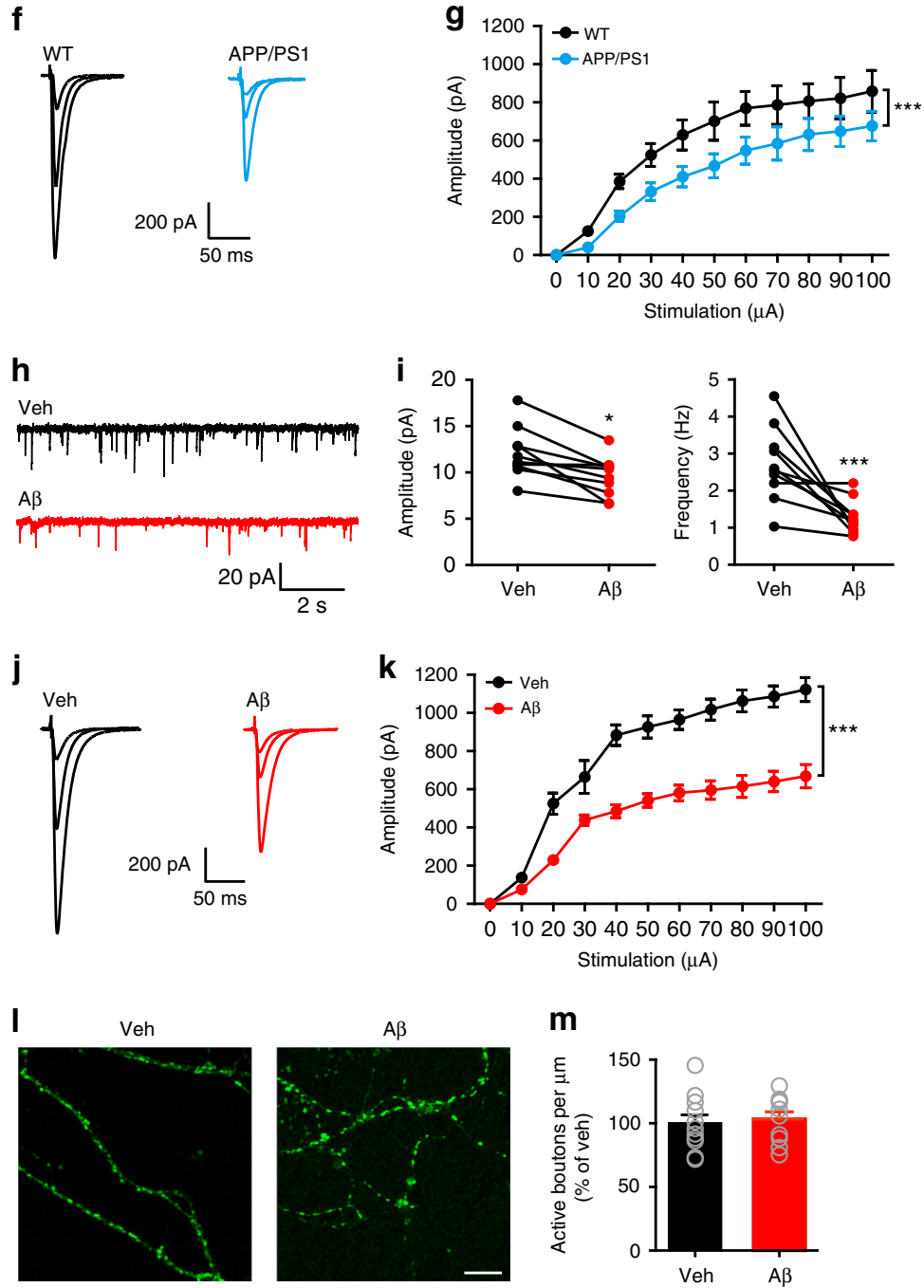

frequency is not due to a decrease in the number of active boutons and suggest that early synaptic deficits in $\mathrm{AD}$ mouse models may involve a presynaptic mechanism other than reducing the active pool of synaptic vesicles.

A decrease in mEPSC frequency may also be due to a reduction in presynaptic release Pr. We thus first investigated whether $A \beta$ elevation enhances paired-pulse facilitation (PPF) at the SC-CA1 synapse, as the degree of PPF is inversely related to Pr. We found that PPF was significantly increased in 6-7-month-old APP/PS1 (Fig. 2a, b) and 4-month-old 5xFAD (Supplementary Fig. 4a, b) mice compared to WT controls. In 4-month-old APP/PS1 (Supplementary Fig. 4a, b) and 6-7-month-old M146V 
Fig. 1 Excitatory synaptic deficits in 6-7-month-old APP/PS1 mice involve a presynaptic mechanism independent of altered bouton density.

a-c Representative Golgi staining of apical dendrites (a) and quantification of density of different types of spines (b) and total spine density (c) in CA1 pyramidal neurons in WT and APP/PS1 mice. Bar, $5 \mu \mathrm{m}$. $t$ test; ${ }^{*}, P<0.05 ; N=10-19$ per group. d, e Representative traces (d) of mEPSCs in CA1 pyramidal neurons and cumulative plots and mean values (insets) (e) of mEPSC amplitude (left) and frequency (right) in WT and APP/PS1 mice. KolmogorovSmirnov test (cumulative plots), ${ }^{\star \star \star} P<0.001 ; t$ test (insets), ${ }^{\star \star} P<0.01 ; N=10-11$ per group. $\mathbf{f}, \mathbf{g}$ Representative traces of SC-CA1 EPSCs evoked by stimulus intensities of 10,30 , and $100 \mu \mathrm{A}(\mathbf{f})$ and quantification of EPSC amplitude to stimulus intensity (g) in WT and APP/PS1 mice. Two-way ANOVA with post hoc Bonferroni test; animal, $F_{(1,132)}=30.22, P<0.001$; stimulation, $F_{(10,132)}=27.23, P<0.001 ;{ }^{\star \star \star} P<0.001 ; N=5-9$ per group. $\mathbf{h}$, i Representative traces (h) of mEPSCs in CA1 pyramidal neurons and quantification (i) of mEPSC amplitude (left) and frequency (right) in WT hippocampal slices before (vehicle, Veh) and after $A \beta$ treatment. $t$ test; ${ }^{\star} P<0.05 ;{ }^{\star \star \star} P<0.001 ; N=10$ per group. $\mathbf{j}$, $\mathbf{k}$ Representative traces of SC-CA1 EPSCs evoked by stimulus intensities of $10,20,100 \mu \mathrm{A}(\mathbf{j})$ and quantification of EPSC amplitude to stimulus intensity ( $\mathbf{g}$ ) in WT hippocampal slices before $(V e h)$ and after $A \beta$ treatment. Two-way ANOVA with post hoc Bonferroni test; animal, $F_{(1,132)}=244.0, P<0.001 ;$ stimulation, $F_{(10,132)}=83.89, P<0.001$; ${ }^{\star \star \star} P<0.001 ; N=7$ per group. I, m Representative images of FM1-43-labeled active boutons (I) and quantification of relative FM1-43-labeled bouton density $(\mathbf{m})$ in cultured hippocampal neurons treated with Veh or $A \beta$. Bar, $50 \mu \mathrm{m}$. $t$ test; $P>0.05 ; N=10-11$ per group. Data are mean $\pm S E M$. CF cumulative frequency. Source data are provided as a Source Data file

a

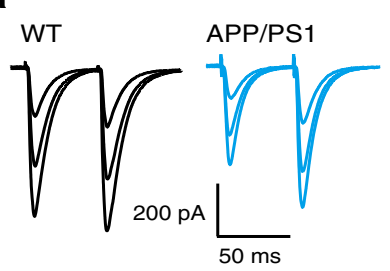

e

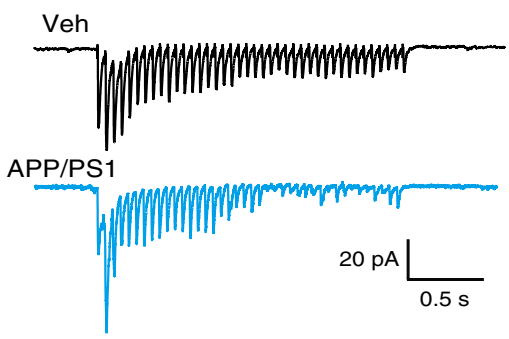

f

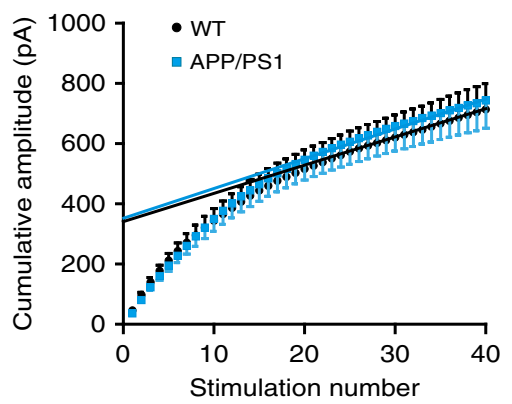

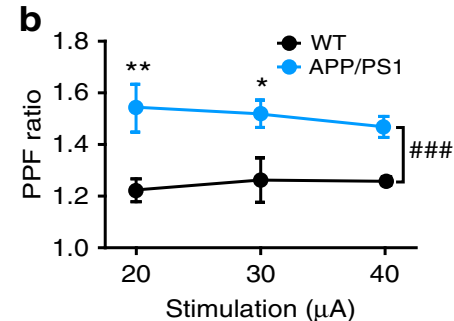

c
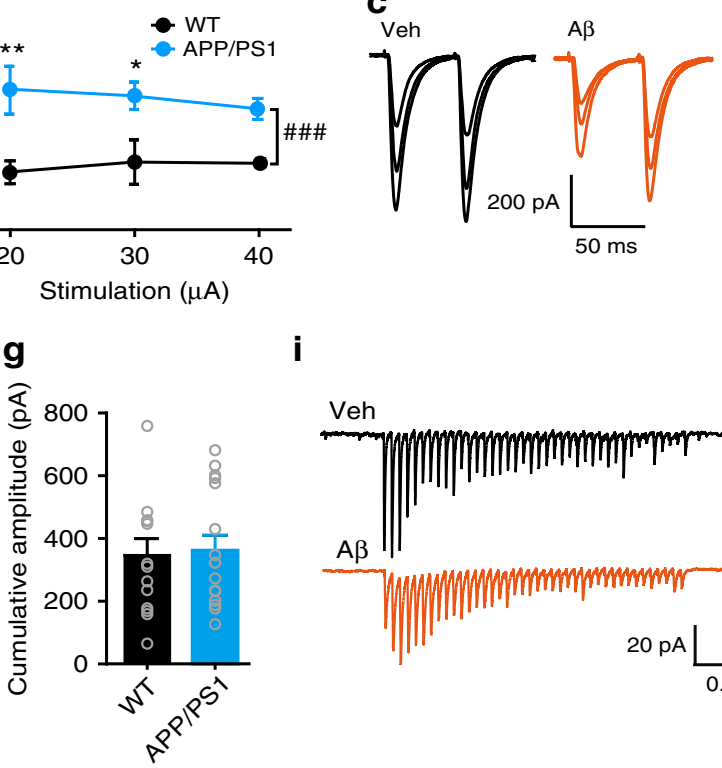

h

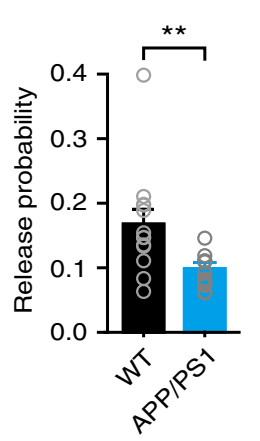

i

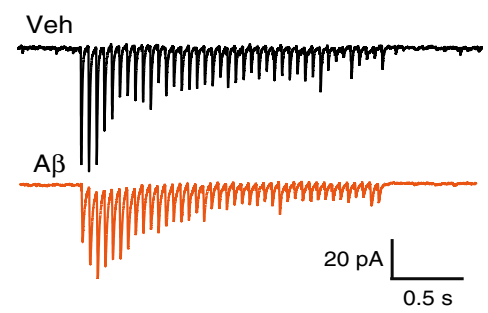

j

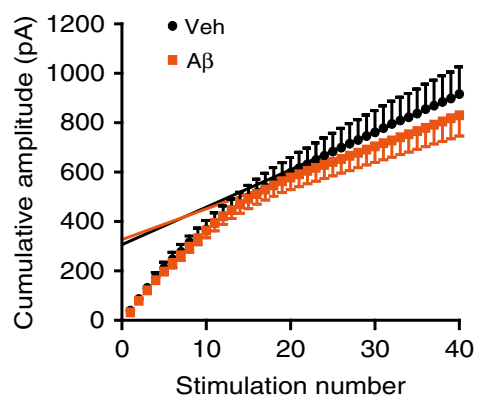

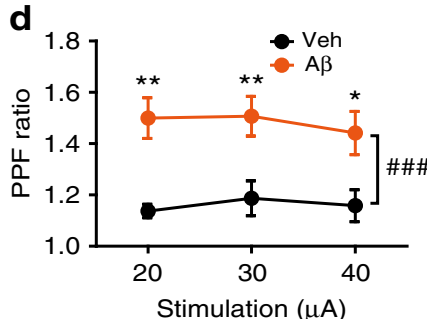

$\mathbf{k}$

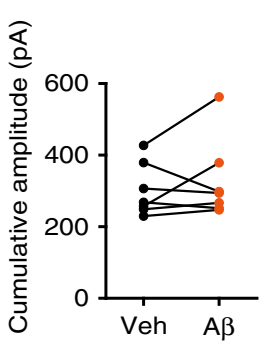

I

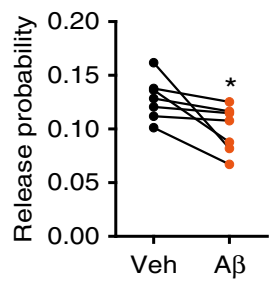

Fig. 2 High nanomolar A $\beta$ oligomers suppress presynaptic release probability at the SC-CA1 synapse. a-d Representative traces (a, c) and quantification $(\mathbf{b}, \mathbf{d})$ of PPF of SC-CA1 EPSCs evoked by stimulus intensities of 20, 30, and $40 \mu \mathrm{A}$ in 6-7-month-old WT and APP/PS1 mice (a, b) and in oligomeric $\mathrm{A} \beta(400 \mathrm{nM})$-treated hippocampal slices relative to vehicle (Veh)-treated ones (c, d). Two-way ANOVA with post hoc Bonferroni test; in $\mathbf{b}$ : animal, $F_{(1,24)}=32.67, P<0.001$; stimulation, $F_{(2,24)}=0.2378, P=0.89$; in $\mathbf{d}$ : treatment, $F_{(1,24)}=34.63, P<0.001$; stimulation, $F_{(2,24)}=0.029, P=0.79$; $\# \# \# P<0.001 ;{ }^{\star} P<0.05 ;{ }^{\star \star} P<0.01 ; N=5$ per group. e Representative traces showing the response of $C A 1$ pyramidal neurons to $20 \mathrm{~Hz}$ stimulation of the SC in 6-7-month-old WT and APP/PS1 mice. f-h Cumulative amplitude analysis showing the magnitude of the cumulative amplitude (f), RRP size (f, $\mathbf{g}$ ), defined as the $y$-intercept of the linear portion of the curve, and the release probability (h), calculated as mean EPSC amplitude (the mean value of the 1st EPSCs) divided by RRP size, in WT and APP/PS1 mice. $t$ test; ${ }^{\star \star} P<0.05 ; N=13-15$ per group. $\mathbf{i}$ Representative traces showing the response of the SC-CA1 synapse to $20 \mathrm{~Hz}$ stimulation before (Veh) and after bath application of $400 \mathrm{nM}$ A $\beta$ oligomers in WT hippocampal slices. $\mathbf{j}$-I Cumulative amplitude analysis (j) showing the effect of $400 \mathrm{nM} \mathrm{A} \beta$ oligomers on RRP size (j, $\mathbf{k})$ and the release probability $(\mathbf{I})$ at the SC-CA 1 synapse. $t$ test; ${ }^{\star} P<0.05 ; N=7$ per group. Data are mean \pm SEM. Source data are provided as a Source Data file 
(Supplementary Fig. 4c, d) mice, however, PPF was unchanged in comparison to WT mice, which is also reported in 3-month-old APP/PS1 mice ${ }^{43}$. Similarly, $A \beta_{42}$ oligomers induced a significant increase in PPF in WT animals (Fig. $2 c, d$ ). These results suggest that pathogenic $A \beta$-induced synaptic deficits are due to a reduction in Pr. To directly determine if Pr was suppressed in $\mathrm{APP} / \mathrm{PS} 1$ mice and in A $\beta$-treated brain slices from WT mice, we used a repeated stimulation protocol to estimate the readily releasable pool (RRP) size and $\operatorname{Pr}$ (Fig. 2e-1). Repeated stimulation $(20 \mathrm{~Hz})$ revealed a significant reduction in $\mathrm{Pr}$ in APP/PS1 mice (Fig. 2h) and in A $\beta$-treated brain slices from WT mice (Fig. 2l), although the RRP size did not change (Fig. 2g, k). Taken together, these results indicate that $A \beta$ accumulation reduces $\mathrm{Pr}$ in the hippocampus.

To establish that the presynaptic deficit is due to an elevated $A \beta$ level in 6-7-month-old APP/PS1 mice, we investigated whether reducing the $A \beta$ level could restore hippocampal synaptic transmission. We first treated 6-7-month-old APP/PS1 and WT mice with LY-411575, a $\gamma$-secretase inhibitor that is known to decrease interstitial fluid levels of $A \beta^{18,44}$, and confirmed the effectiveness of LY-411575 by the elevated levels of C-terminal fragments (CTFs) after treatment (Supplementary Fig. 5a). We did not measure A $\beta$ levels to indicate LY-411575 activity because existing plaques in these mice are not reduced by LY-411575 44,45 . Treatment with LY-411575 significantly increased CA1 mEPSC frequency in CA1 pyramidal neurons (Supplementary Fig. 5b, c) and SC-CA1 EPSC amplitude (Supplementary Fig. 5d, e) and reduced PPF at the SC-CA1 synapse (Supplementary Fig. 5f, g) in APP/PS1 mice, implicating that inhibiting $A \beta$ generation enhanced $P r$ in these mice. We next examined whether directly blocking $A \beta$ with a specific human $A \beta$ antibody could restore the decreased Pr in APP/PS1 mice. Longterm incubating hippocampal slices from APP/PS1 mice with $6 \mathrm{E} 10\left(2 \mu \mathrm{g} \mathrm{ml}^{-1},>5 \mathrm{~h}\right)$ strongly increased mEPSC frequency (Fig. 3a, b) and evoked EPSC amplitude (Fig. 3c, d) and suppressed PPF (Fig. 3e, f), indicating that blocking $A \beta$ with $6 \mathrm{E} 10$ indeed restored the presynaptic defect in these mice. Although this long-term maintenance of hippocampal slices in vitro caused a rundown in the baseline transmission in both WT and APP/PS1 mice, the effect of blocking $\mathrm{A} \beta$ with $6 \mathrm{E} 10$ on restoring synaptic transmission in APP/PS1 mice to the level in WT mice was remarkable. Taken together, our results showed that elevated $A \beta$ levels were essential for reducing Pr in APP/PS1 mice.

$\mathrm{PIP}_{2}$ depletion by $\mathrm{A} \boldsymbol{\beta}$-induced activation of mGluR5 reduces Pr. One of the key mechanisms controlling Pr involves a vesicle membrane-anchoring event preceding the formation of the SNARE complex. As a crucial phosphoinositide interacting with membrane-binding proteins, $\mathrm{PIP}_{2}$ has been shown to play an important role in vesicle release via synaptotagmin $1-\mathrm{PIP}_{2}$ binding, and its level in the membrane, thus, is tightly associated with $\mathrm{Pr}^{46}$. We found that the $\mathrm{PIP}_{2}$ level was significantly decreased in 6-7-month-old APP/PS1 mice (Supplementary Fig. 6). This is consistent with the decreased $\mathrm{Pr}$ in $\mathrm{AD}$ mouse models. To further test if $\mathrm{A} \beta$ can deplete $\mathrm{PIP}_{2}$ in axons, we immunostained and biochemically measured $\mathrm{PIP}_{2}$ in cultured hippocampal neurons in control, vehicle (DMSO)-treated, or $\mathrm{A} \beta_{42}$ oligomer-treated medium (Fig. $4 \mathrm{a}-\mathrm{c}$ ). In comparison to control and DMSO treatments, $\mathrm{A} \beta$ treatment rapidly and significantly suppressed total $\mathrm{PIP}_{2}$ (Fig. 4c) and axonal (MAP2 ${ }^{-}$, NF ${ }^{+}$) and dendritic $\left(\mathrm{MAP}^{+}, \mathrm{NF}^{+}\right) \mathrm{PIP}_{2}$ (Fig. 4a, b). Although the anti-PIP $\mathrm{P}_{2}$ antibody we used cross-reacts with phosphatidylinositol-3,4,5-trisphosphate $\left(\mathrm{PIP}_{3}\right)$ (Supplementary Fig. 7a), we believe $A \beta$-induced suppression of $\mathrm{PIP}_{2}$ is valid since $\mathrm{PIP}_{3}$ is significantly less abundant than $\mathrm{PIP}_{2}{ }^{47}$ and the ELISA kit we used is highly specific to $\mathrm{PIP}_{2}$ (Supplementary Fig. 7b). To test if adding $\mathrm{PIP}_{2}$ back to $\mathrm{A} \beta$-treated neurons was sufficient to restore $A \beta$-induced presynaptic defect, we recorded miniature excitatory autaptic currents (mEACs) from individually inhabited neurons grown on collagen-poly-D-lysine (PDL) islands (Fig. 4d). We first established that $A \beta$-induced suppression of mEAC frequency was similar to that of mEPSC frequency (Fig. 4e, f). We then filled the patch pipettes with an internal solution containing $200 \mu \mathrm{M}$ diC8-PIP 2 , assuming PIP $_{2}$ would be incorporated into the axon influencing neurotransmitter release. Indeed, intracellularly applied $\mathrm{PIP}_{2}$ rescued $\mathrm{A} \beta$-induced inhibition of mEAC frequency, whereas intracellularly applied $\mathrm{PIP}_{2}$ did not affect baseline mEAC frequency (Fig. 4e, f). These results indicate that $\mathrm{A} \beta$-associated $\mathrm{PIP}_{2}$ depletion accounts for $\mathrm{A} \beta$-induced presynaptic effect.

$\mathrm{A} \beta$-induced rapid $\mathrm{PIP}_{2}$ depletion confirms a predominant $\mathrm{PIP}_{2}$ hydrolysis process evoked by $A \beta$ oligomers ${ }^{38}$. Increased PLC activity, thus, may result in $\mathrm{A} \beta$-induced $\mathrm{PIP}_{2}$ depletion. To test this hypothesis, we applied PLC inhibitor U73122 in the culture medium to block PLC activity in primary hippocampal neurons before oligomeric $A \beta_{42}$ treatment. In the presence of U73122, $\mathrm{A} \beta_{42}$ oligomers no longer exerted the inhibitory effect on $\mathrm{PIP}_{2}$ levels in axons and dendrites (Fig. 5a, b). U73122 alone did not change $\mathrm{PIP}_{2}$ levels in neuronal processes (Fig. $5 \mathrm{a}, \mathrm{b}$ ). These results indicate that $\mathrm{A} \beta$-induced $\mathrm{PIP}_{2}$ depletion is mainly due to an $\mathrm{A} \beta$ triggered, PLC-mediated $\mathrm{PIP}_{2}$ hydrolytic event. We next investigated whether blocking PLC activity prevented the presynaptic deficit induced by oligomeric $A \beta_{42}$. In the presence of U73122, oligomeric $A \beta_{42}$-induced suppression of SC-CA1 EPSCs was partially restored (Fig. 5c-e). Notably, U73122 treatment reduced oligomeric $A \beta_{42}$-induced inhibition of mEPSC frequency but not amplitude (Fig. 5f, g), suggesting that blocking PLC prevented $A \beta$-induced inhibition of Pr. Blocking A $\beta$-induced inhibition of $\mathrm{Pr}$ via inhibiting PLC was further proved by examining PPF at the SC-CA1 synapse, as a prior application of U73122 prevented $A \beta$-induced increase in the paired-pulse ratio (Fig. 5h, i). In addition, U73122 alone did not change the frequency and amplitude of mEPSCs in CA1 pyramidal neurons and the PPF at the SC-CA1 synapse in WT animals (Supplementary Fig. 8a-d). Furthermore, we explored which PLC isoforms were involved in $\mathrm{A} \beta$-induced $\mathrm{PIP}_{2}$ hydrolysis in neurites using the RNA-interference approach (Supplementary Fig. 9a, b). Knocking down either PLC $\beta 1$ or $\beta 4$ significantly ameliorated $A \beta$ induced suppression of $\mathrm{PIP}_{2}$ levels in both dendrites and axons (Supplementary Fig. 9c, d), indicating that both PLC $\beta 1$ and $\beta 4$ contribute to $\mathrm{A} \beta$-induced $\mathrm{PIP}_{2}$ hydrolysis in hippocampal neurons. Taken together, these results prove that $A \beta$-induced elevation of PLC activity underlies $\mathrm{PIP}_{2}$ depletion and $\mathrm{Pr}$ reduction.

One of the key routes leading to PLC activation is via ligand binding to Gaq-coupled GPCRs. $A \beta$ has been shown to activate many GPCRs, including mGluR $5^{32-34}$, a subtype of group I metabotropic glutamate receptors (mGluRs). We found that mGluR5 was expressed in neuronal processes, although axonal mGluR5 is less abundant than dendritic mGluR5 (Fig. 6a, b). Thus, we studied whether mGluR5 mediated A $\beta$-induced $\mathrm{PIP}_{2}$ depletion and the subsequent presynaptic defect. We first examined whether a group I mGluR agonist (S)-3,5-Dihydroxyphenylglycine (DHPG) (Fig. 6) exerted similar effects as A $\beta$ oligomers (Fig. 4). Application of DHPG in the culture medium significantly decreased $\mathrm{PIP}_{2}$ levels in axons and dendrites in primary hippocampal neurons (Fig. 6c, d). Unlike A $\beta$, DHPG still depleted $\mathrm{PIP}_{2}$ in neurites in the presence of an antibody (6D11) against $\mathrm{PrPC}$, indicating that oligomeric $\mathrm{A} \beta$-induced $\mathrm{PIP}_{2}$ hydrolysis requires activation of mGluR5 with the aid of $\mathrm{PrPC}^{2}$ (Supplementary Fig. 10). Functionally, DHPG inhibited mEPSC 
a
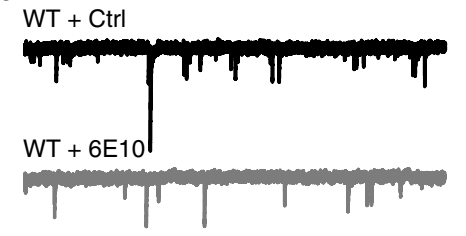

APP/PS1 + Ctrl

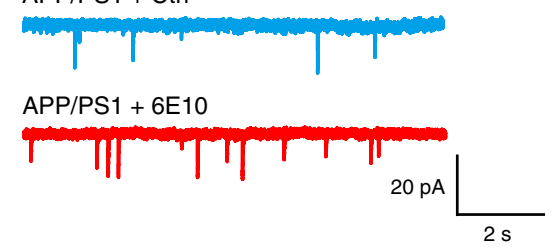

C

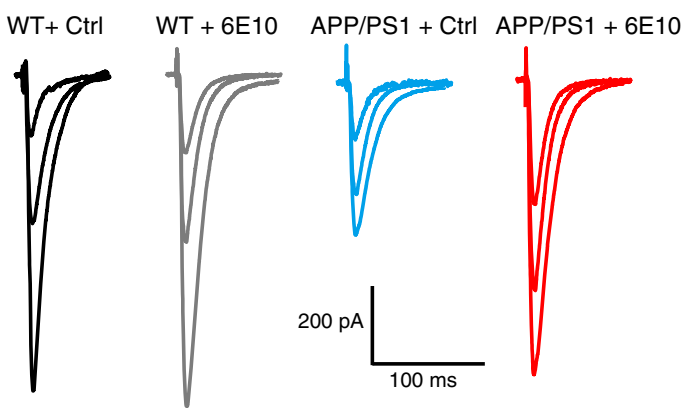

b

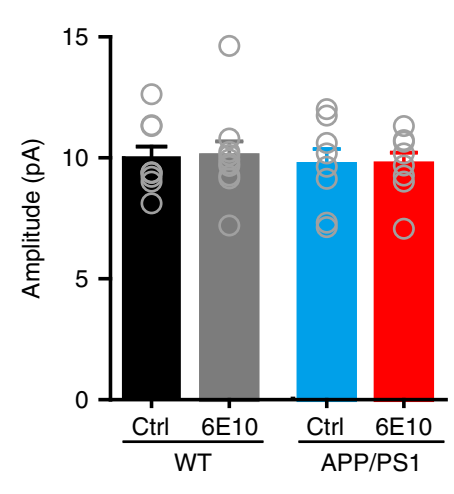

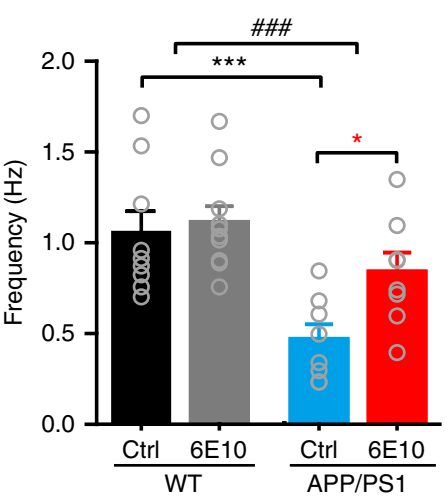

e

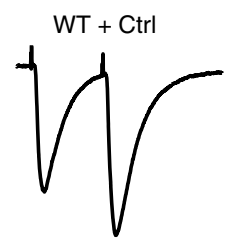

1

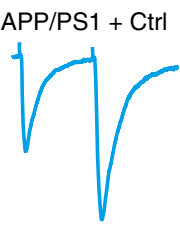

APP/PS1 $+6 \mathrm{E} 10$

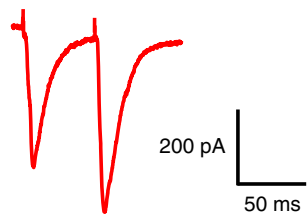

d
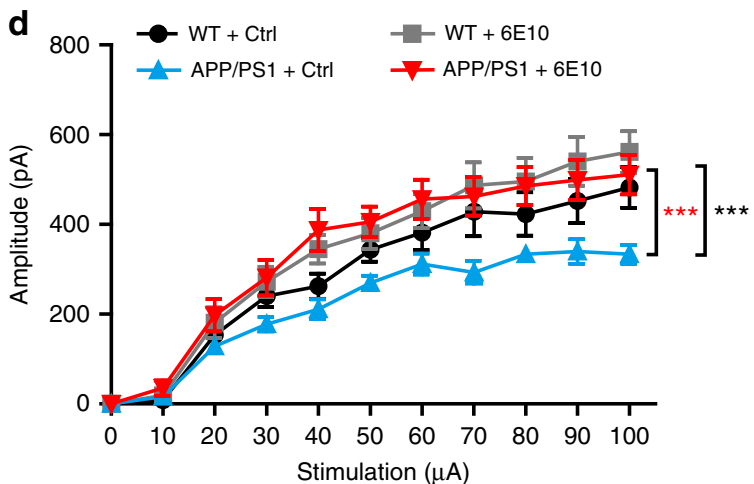

$\mathbf{f}$

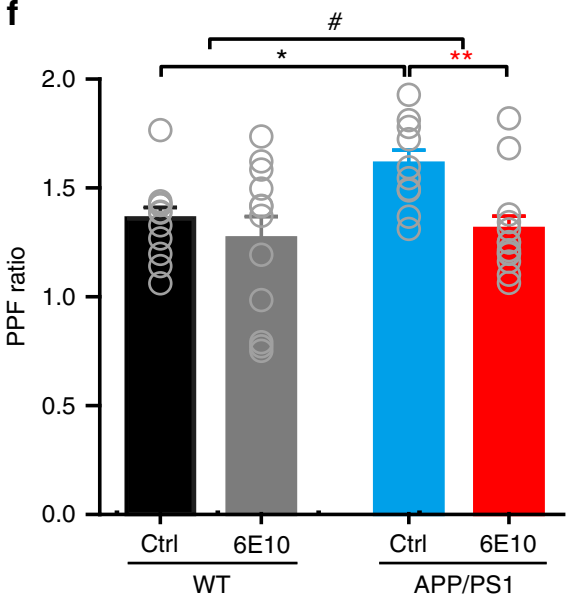

Fig. 3 Blocking A $\beta$ with anti- $\beta$-amyloid antibody 6 E10 rescues the presynaptic deficit in hippocampal slices from 6-7-month-old APP/PS1 mice. a, b Representative traces (a) of mEPSCs in CA1 pyramidal neurons and quantification (b) of mEPSC amplitude (left) and frequency (right) in hippocampal slices from WT and APP/PS1 mice incubated in control (Ctrl) ACSF or ACSF containing 6E10. Two-way ANOVA with post hoc Bonferroni test; left panel: animal, $F_{(1,31)}=0.286, P=0.597$; treatment, $F_{(1,31)}=0.0119, P=0.914$; right panel: animal, $F_{(1,31)}=18.66, P<0.001 ;$ treatment, $F_{(1,31)}=4.64, P=0.039 ;{ }^{\star} P$ $<0.05$; ${ }^{\star \star \star} P<0.001 ; \# \# P<0.001$ (APP/PS1 vs. WT); $N=8-10$ per group. $\mathbf{c}$, $\mathbf{d}$ Representative traces of SC-CA1 EPSCs evoked by stimulus intensities of 20,40 , and $100 \mu \mathrm{A}$ (c) and quantification of EPSC amplitude to stimulus intensity (d) in hippocampal slices from WT and APP/PS1 mice incubated in Ctrl ACSF or ACSF containing 6E10. Two-way ANOVA with post hoc Bonferroni test; animal, $F_{(3,341)}=19.694, P<0.001$; treatment, $F_{(10,341)}=32.140, P<$ $0.001 ;{ }^{\star \star \star} P<0.001$ (compared with APP/PS1 + Ctrl group); $N=7-10$ per group. e, $\mathbf{f}$ Representative traces (e) and quantification (f) of PPF of SC-CA1 EPSCs in hippocampal slices from WT and APP/PS1 mice incubated in Ctrl ACSF or ACSF containing 6E10. Two-way ANOVA with post hoc Bonferroni test; animal, $F_{(1,43)}=4.069, P=0.049$; treatment, $F_{(1,43)}=7.219, P=0.01 ;{ }^{\star} P<0.05 ;{ }^{\star \star} P<0.01 ; \# P<0.05$ (APP/PS1 vs. WT); $N=10-13$ per group. Source data are provided as a Source Data file

frequency in CA1 pyramidal neurons (Fig. 6e, f) and increased PPF at the SC-CA1 synapse (Fig. 6g, h), indicating that activation of group I mGluRs induced mainly a presynaptic effect. Unlike A $\beta$, DHPG did not alter mEPSC amplitude (Fig. 6e, f), suggesting that activation of group I mGluRs was not involved in $\mathrm{A} \beta$ induced suppression of mEPSC amplitude.
We next investigated whether inhibiting mGluR5 hampered the effectiveness of oligomeric $\mathrm{A} \beta_{42}$ on $\mathrm{PIP}_{2}$ depletion and $\mathrm{Pr}$ reduction. In the presence of a selective mGluR5 antagonist 3-((2Methyl-4-thiazolyl)ethynyl)pyridine (MTEP), oligomeric $\mathrm{A} \beta_{42}$ no longer suppressed $\mathrm{PIP}_{2}$ levels in neurites in primary hippocampal neurons (Fig. 6i, j). MTEP treatment partially occluded A $\beta$ - 
a
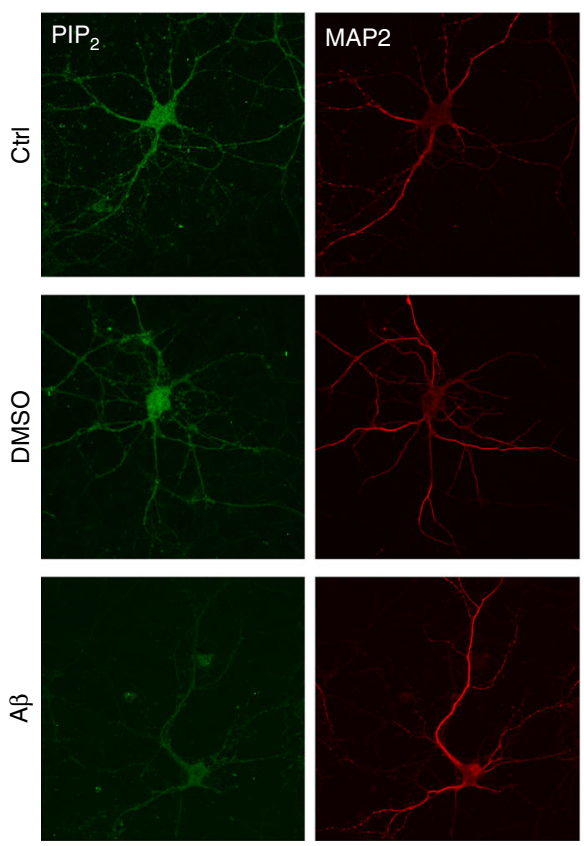
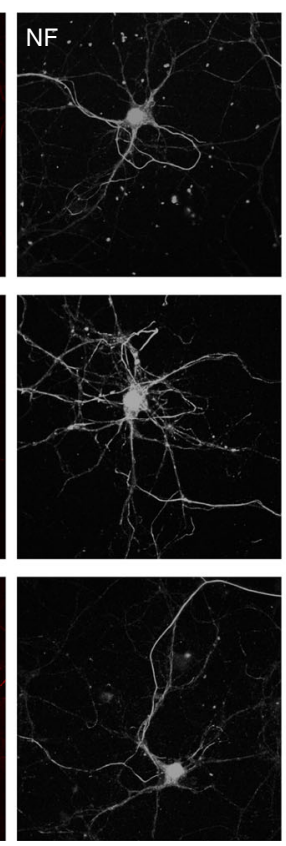
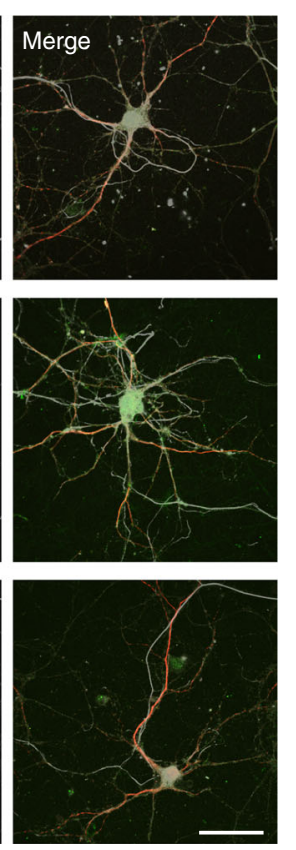

b
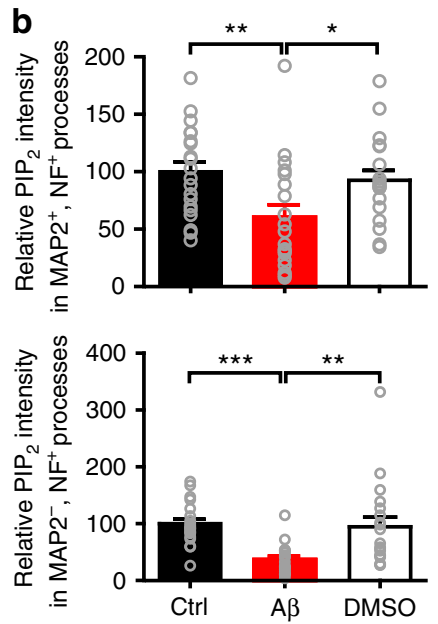

C

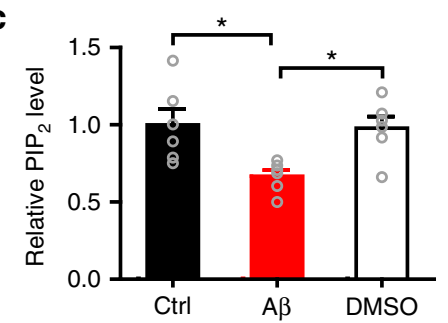

d
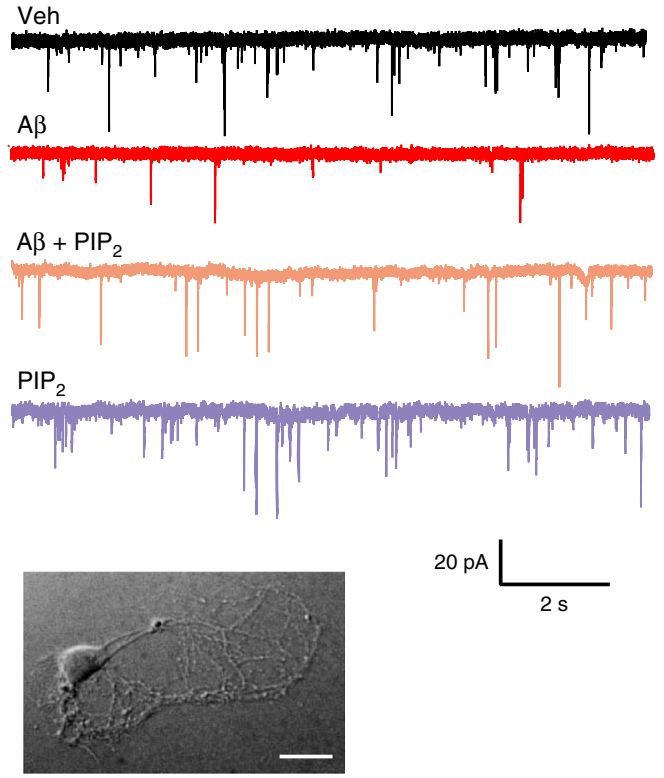

e
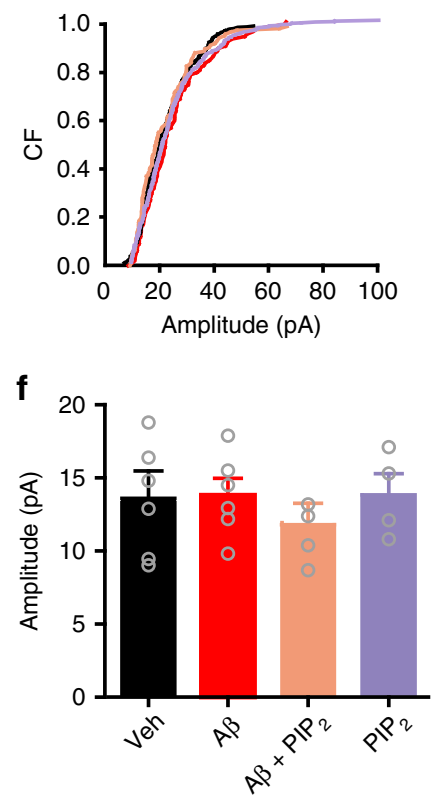
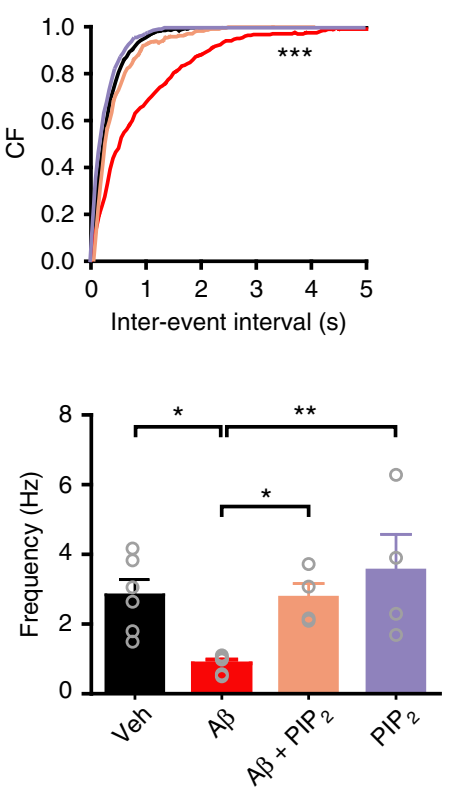

Fig. 4 Reduced axonal $\mathrm{PIP}_{2}$ accounts for oligomeric $A \beta$-induced suppression of presynaptic release probability at the SC-CA1 synapse. a Confocal images of primary hippocampal neurons showing colocalization of $\mathrm{PIP}_{2}, \mathrm{MAP2}$, and neurofilament (NF) along neuronal processes in control, DMSOtreated, and oligomeric $A \beta$-treated hippocampal neurons. Bar, $50 \mu \mathrm{m}$. b Histograms showing oligomeric $A \beta$ suppresses $P_{2} P_{2}$ levels significantly in both dendrites (MAP2 ${ }^{+}, \mathrm{NF}^{+}$, upper panel) and axons (MAP2 ${ }^{-}, \mathrm{NF}^{+}$, bottom panel). One-way ANOVA with post hoc Dunnett's test; $F_{(2,55)}=4.95$ (upper); $F_{(2,55)}=9.39$ (bottom); ${ }^{\star} P<0.05 ;{ }^{\star \star} P<0.01 ;{ }^{\star \star \star} P<0.001 ; N=19-20$ per group. c Quantification of PIP 2 levels measured with ELISA showing oligomeric $\mathrm{A} \beta$ suppresses $\mathrm{PIP}_{2}$ in cultured hippocampal neurons. One-way ANOVA with post hoc Dunnett's test; $F_{(2,15)}=5.87 ;{ }^{\star} P<0.05 ; N=6$ per group. d Representative traces of mEACs recorded from isolated hippocampal neurons (an example shown in inset at bottom) in vehicle-treated medium $(V e h)$, oligomeric $A \beta$-supplemented medium $(A \beta)$, oligomeric $A \beta$-supplemented medium with intracellular application of $P I P_{2}\left(A \beta+P I P_{2}\right)$, or vehicletreated medium with intracellular application of $\mathrm{PIP}_{2}\left(\mathrm{PIP}_{2}\right)$. Bar, $50 \mu \mathrm{m}$. e, $\mathbf{f}$ Cumulative plots (e) and mean values (f) of mEAC amplitude (left) and frequency (right) in isolated hippocampal neurons in various conditions. Kolmogorov-Smirnov test in e; one-way ANOVA with post hoc Dunnett's test in f, $F_{(3,16)}=0.54$ (amplitude); $F_{(3,16)}=5.47$ (frequency); ${ }^{\star} P<0.05 ;{ }^{\star \star} P<0.01 ;{ }^{\star \star \star} P<0.001 ; N=4-6$ per group. Data are mean \pm SEM. Source data are provided as a Source Data file 

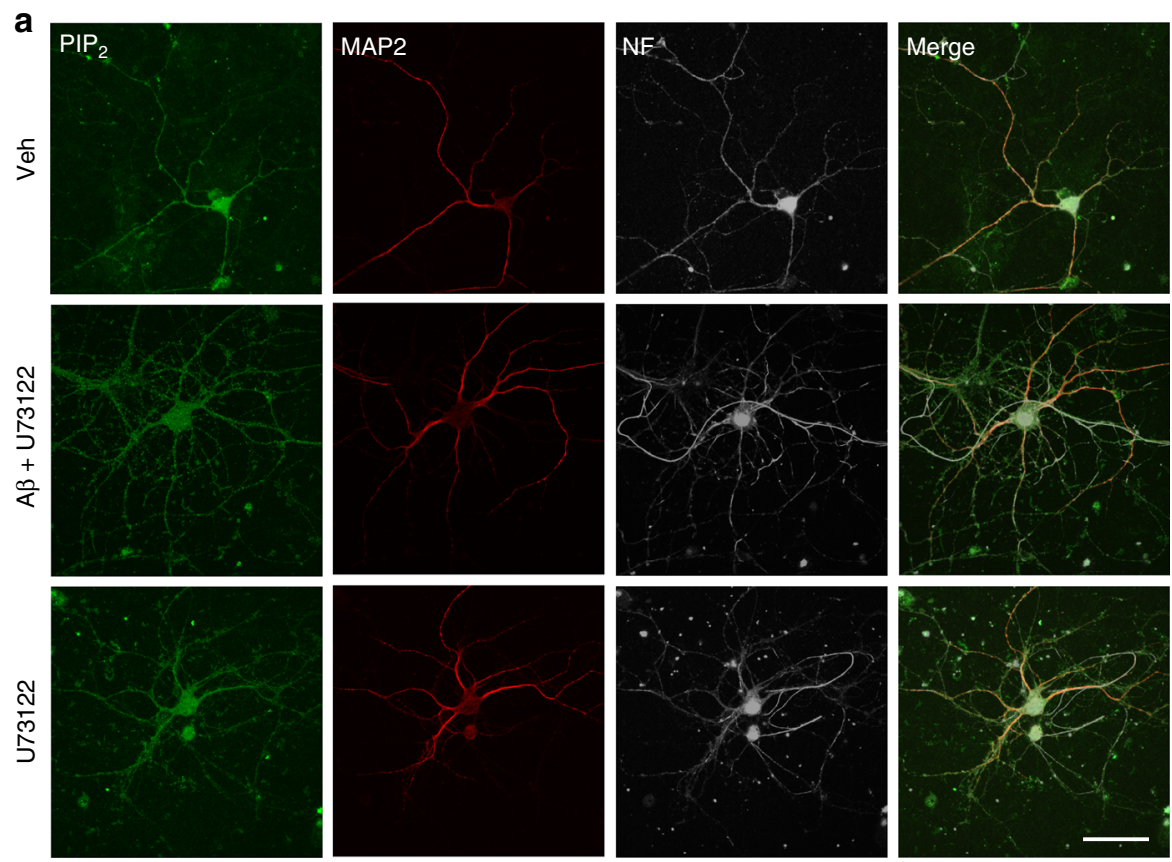

C
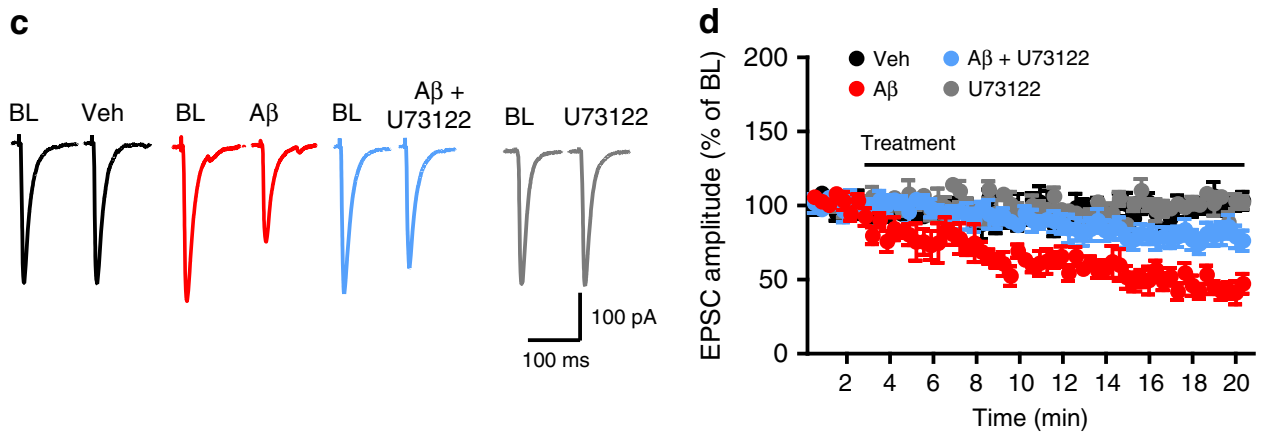

h

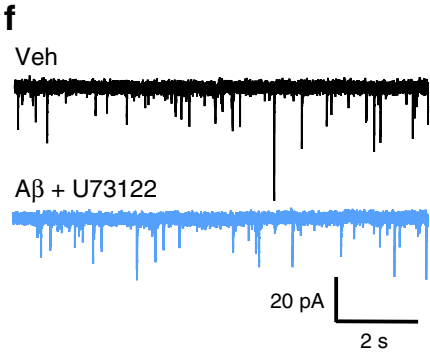

g

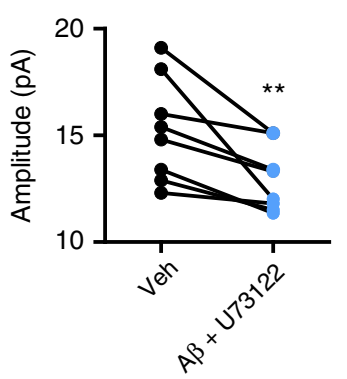

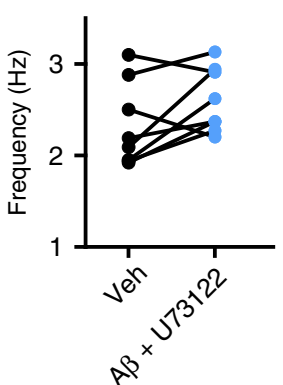
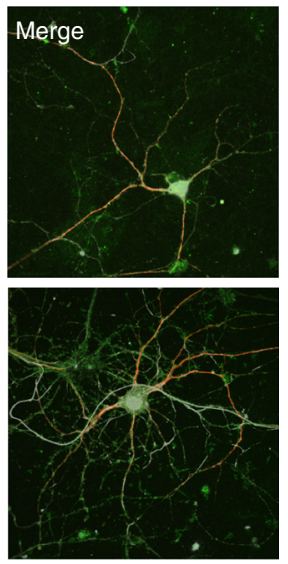

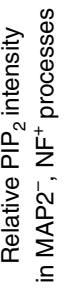
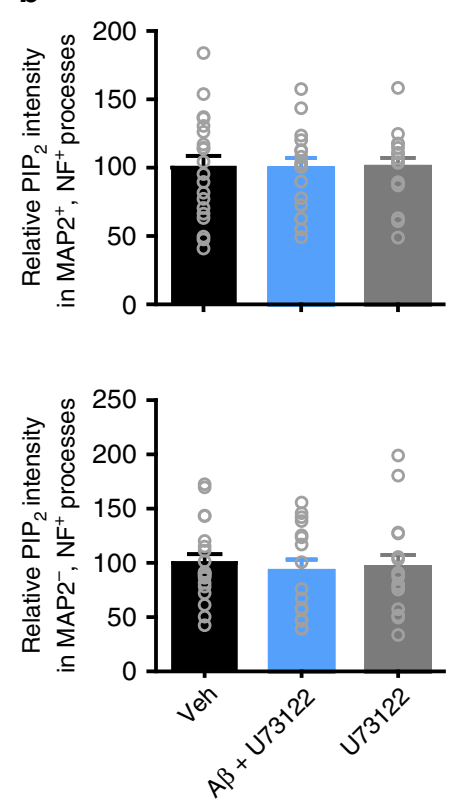
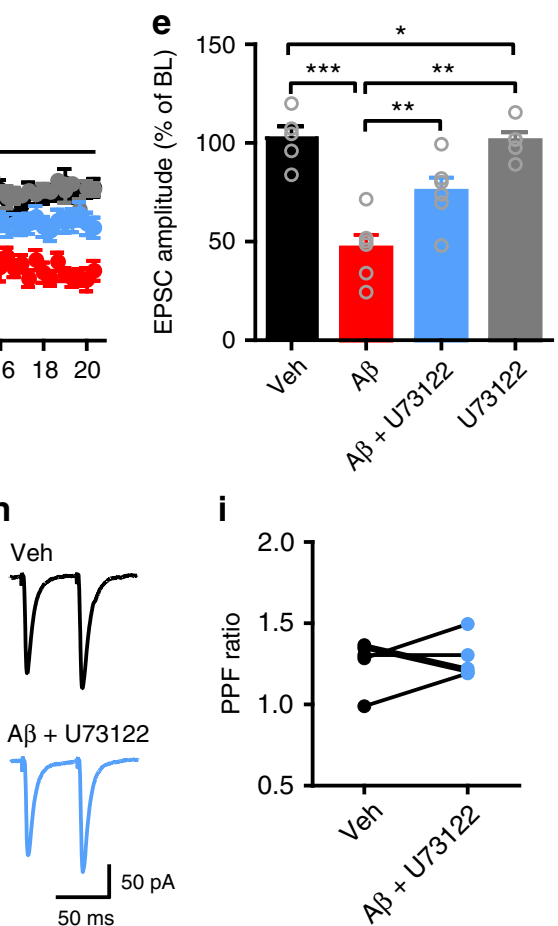

Fig. 5 Oligomeric $A \beta$-induced $\mathrm{PIP}_{2}$ reduction and presynaptic deficit are prevented by inhibiting PLC. a Confocal images of primary hippocampal neurons showing the effect of oligomeric $A \beta$ on $\mathrm{PIP}_{2}$ levels in neuronal processes in the presence of PLC blocker U73122. Bar, $50 \mu \mathrm{m}$. $\mathbf{b}$ Quantification of relative $\mathrm{PIP}_{2}$ intensity in dendrites (upper panel) and axons (bottom panel) showing U73122 prevents $A \beta$-induced suppression of $\mathrm{PIP}$ in neuronal processes. One-way ANOVA with post hoc Dunnett's test; $F_{(2,49)}=0.007$ (upper); $F_{(2,49)}=0.12$ (bottom); $P>0.05 ; N=16-20$ per group. c, d Representative traces (c) and the time course of the normalized amplitude (d) of SC-CA1 EPSCs in WT hippocampal slices before (baseline, BL) and

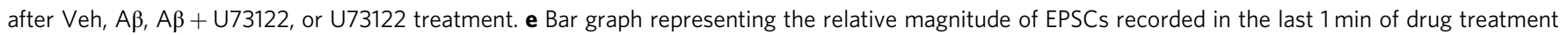
shown in d. One-way ANOVA with post hoc Dunnett's test; $F_{(3,21)}=18.04 ;{ }^{\star} P<0.05 ;{ }^{\star \star} P<0.01 ;{ }^{\star \star \star} P<0.001 ; N=5-6$ per groups. f, $\mathbf{g}$ Representative traces (f) and quantification ( $\mathbf{g}$ ) of mean values of the amplitude (left) and frequency (right) of mEPSCs in CA1 pyramidal neurons before (Veh) and after $\mathrm{A} \beta+\mathrm{U} 73122$ treatment. $t$ test; ${ }^{\star \star} P<0.01 ; N=8$ per group. $\mathbf{h}$, i Representative traces (h) and quantification (i) of PPF of SC-CA1 EPSCs before (Veh) and after $\mathrm{A} \beta+\mathrm{U} 73122$ treatment. $t$ test; $P>0.05 ; N=5$ per group. Data are mean \pm SEM. Source data are provided as a Source Data file 
a
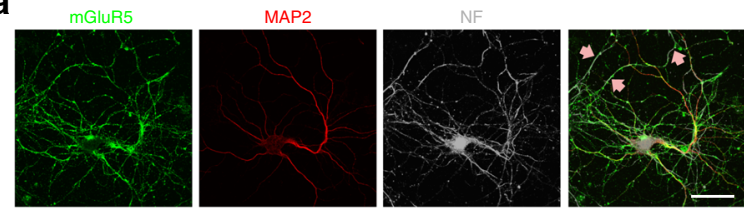

C
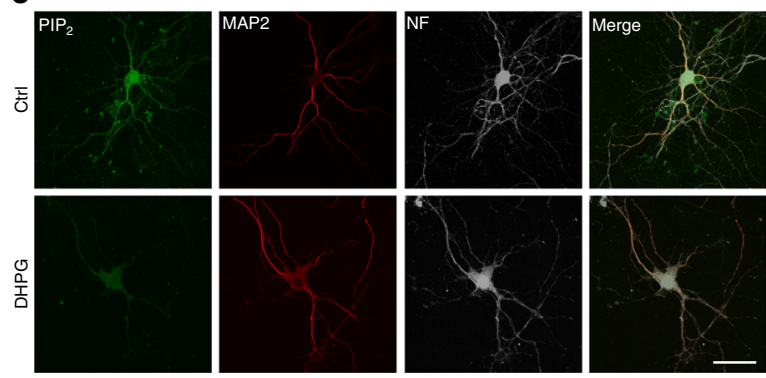

e
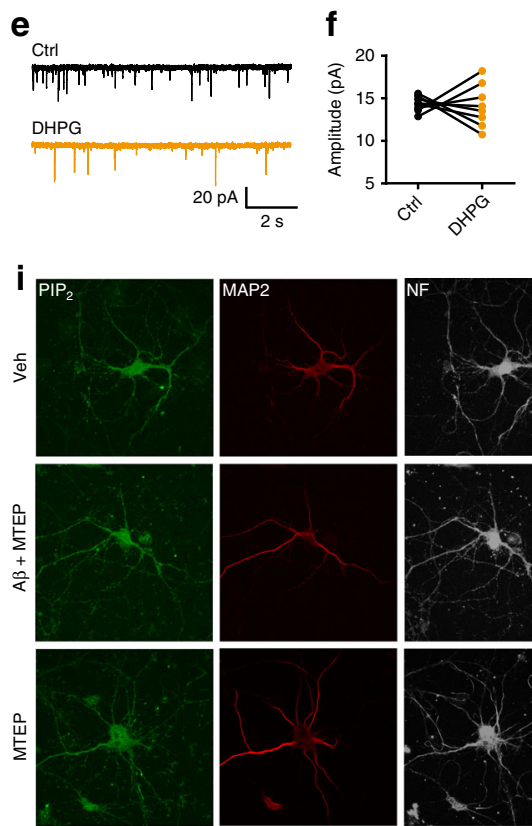

k
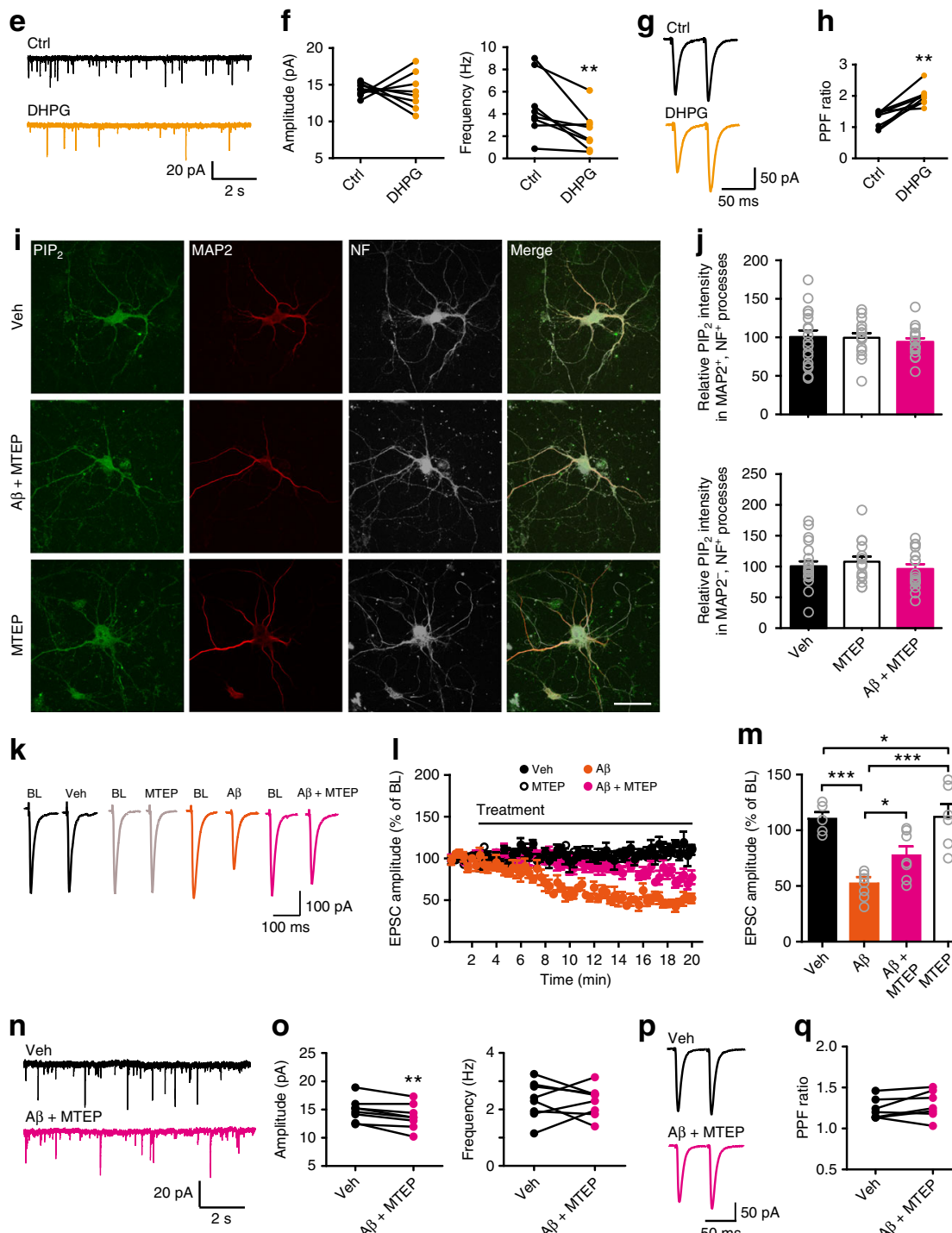

$\mathbf{0}$
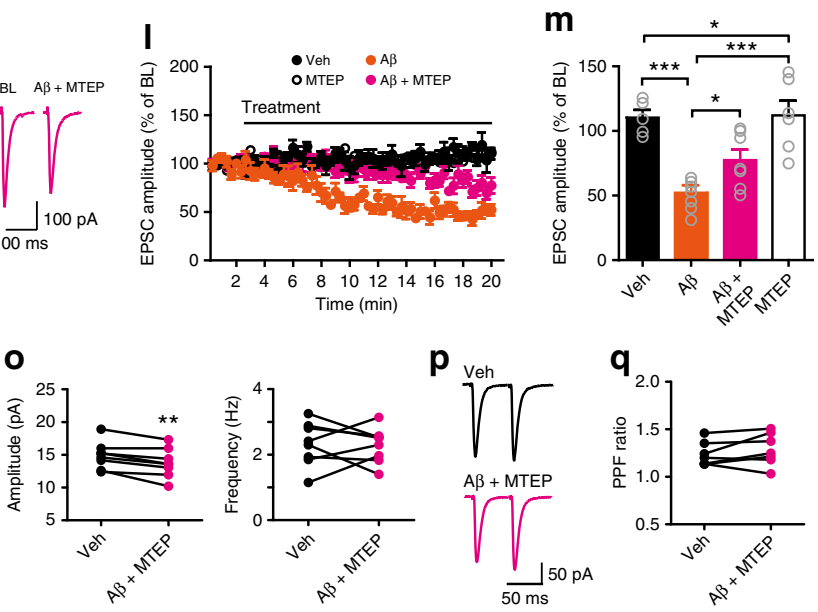

induced inhibition of SC-CA1 EPSCs (Fig. 6k-m), but did not prevent $\mathrm{A} \beta$-induced inhibition of mEPSC amplitude in CA1 pyramidal neurons (Fig. 6n, o), which was consistent with the result showing DHPG did not change mEPSC amplitude (Fig. 6e, f). Importantly, MTEP treatment prevented oligomeric $A \beta_{42^{-}}$ induced changes in mEPSC frequency in CA1 pyramidal neurons (Fig. 6n, o) and PPF at the SC-CA1 synapses (Fig. 6p, q), indicating that blocking mGluR5 ameliorated $\mathrm{A} \beta$-induced $\mathrm{Pr}$ suppression. MTEP alone did not alter $\mathrm{PIP}_{2}$ levels in neurites (Fig. 6i, j), SC-CA1 EPSCs (Fig. 6k-m), mEPSCs in CA1 
Fig. 6 Oligomeric $A \beta$-induced $\mathrm{PIP}_{2}$ reduction and presynaptic deficit involve mGluR5 activation. a Confocal images of primary hippocampal neurons showing colocalization of mGluR5, MAP2, and NF along neurites. Arrows: mGluR5 + axons. Bar, $50 \mu \mathrm{m}$. $\mathbf{b}$ Quantification of relative mGluR5 intensity in neurites. $t$ test; ${ }^{\star} P<0.05 ; N=15$ per group. $\mathbf{c}$ Confocal images of primary hippocampal neurons showing the effect of DHPG on PIP 2 levels in neurites. Bar, $50 \mu \mathrm{m}$. d Quantification of relative PIP 2 intensity in dendrites (upper) and axons (bottom) in control vs. DHPG conditions. $t$ test; ${ }^{\star \star} P<0.01$; ${ }^{\star \star \star} P<0.001 ; N=17-19$ per groups. e-h Representative traces of mEPSCs (e) and PPF ( $\mathbf{g}$ ), and quantification of mean values of mEPSC amplitude (f, left) and frequency (f, right) and PPF ratio (h) before (ctrl) and after DHPG treatment. $t$ test; ${ }^{\star \star} P<0.01 ; N=8$ per group. $\mathbf{i}$ Confocal images of primary hippocampal neurons showing the effect of $A \beta$ on PIP $P_{2}$ levels in neurites in the presence of MTEP. Bar, $50 \mu \mathrm{m}$. $\mathbf{j}$ Quantification of relative PIP $\mathrm{P}_{2}$ intensity in dendrites (upper) and axons (bottom) in control vs. MTEP conditions. One-way ANOVA with post hoc Dunnett's test; $F_{(2,48)}=0.23\left(\right.$ upper); $F_{(2,48)}=0.51$ (bottom); $P>0.05 ; N=16-19$ per group. $\mathbf{k}$, I Representative traces (k) and the time course of the normalized amplitude (I) of SC-CA1 EPSCs in WT hippocampal slices before (BL) and after drug treatment (Veh, A $\beta, A \beta+$ MTEP, or MTEP). $\mathbf{m}$ Quantification of relative amplitude of SC-CA1 EPSCs recorded in the last $1 \mathrm{~min}$ of drug treatment shown in (I). One-way ANOVA with post hoc Dunnett's test; $F_{(3,24)}=14.1 ;{ }^{\star} P<0.05 ;{ }^{\star \star \star \star} P<0.001 ; N=5-7$ per group. $\mathbf{n}-\mathbf{q}$ Representative traces of $\operatorname{mEPSCs}(\mathbf{n})$ and PPF (p), and quantification of mEPSC amplitude (o, left) and frequency (o, right) and PPF ratio $(\mathbf{q})$ before $(V e h)$ and after $A \beta+$ MTEP treatment. $t$ test; ${ }^{\star \star} P<0.01 ; N=7-8$ per group. Data are mean \pm SEM. Source data are provided as a Source Data file

pyramidal neurons (Supplementary Fig. 8e, f), and PPF at the SCCA1 synapse (Supplementary Fig. $8 \mathrm{~g}, \mathrm{~h}$ ) in WT animals. Furthermore, long-term treatment with MTEP $(>3 \mathrm{~h})$ greatly increased CA1 mEPSC frequency (Supplementary Fig. 11a, b) and SC-CA1 EPSC amplitude (Supplementary Fig. 11c, d) and reduced $\mathrm{PPF}$ at the SC-CA1 synapse (Supplementary Fig. 11e, f) in 6-7-month-old APP/PS1 mice, although this long-term maintenance of hippocampal slices in vitro caused a rundown in the baseline transmission. Taken together, these results imply that activation of presynaptic mGluR 5 by $\mathrm{A} \beta$ oligomers contributes to $\mathrm{PIP}_{2}$ depletion-associated reduction in $\mathrm{Pr}$.

Inhibiting presynaptic $\mathrm{PIP}_{2}$ drop rescues $\mathrm{Pr}$ and memory in AD. To establish fully that oligomeric $A \beta$-induced depletion of presynaptic $\mathrm{PIP}_{2}$ underlies Pr reduction, selectively inhibiting A $\beta$ induced hydrolysis of presynaptic $\mathrm{PIP}_{2}$ is essential. One way to control the $\mathrm{PIP}_{2}$ level is to manipulate the responsiveness of Gaqcoupled GPCRs. The mammalian pho eighty-five requiring 3 (Efr3) proteins can control GPCR responsiveness ${ }^{48}$. Indeed, halving Efr $3 a$ in cultured astrocytes from $E f r 3 a^{+/-}$mice resulted in a drastic decrease in DHPG-induced or $A \beta$-induced increase in intracellular $\mathrm{Ca}^{2+}$ concentration $\left(\left[\mathrm{Ca}^{2+}\right]_{\mathrm{i}}\right)$ that could be completely blocked by MTEP (Supplementary Fig. 12), indicating that knocking down Efr3a was an efficient way to suppress mGluR5 responsiveness. Importantly, we found that halving Efr $3 a$ copy number in APP/PS1 mice restored the decreased $\mathrm{PIP}_{2}$ level in the $\mathrm{AD}$ mice (Supplementary Fig. 6). Oligomeric $\mathrm{A} \beta$ treatment was no longer effective in reducing total and neurite $\mathrm{PIP}_{2}$ in cultured hippocampal neurons from Efr $3 a^{+/-}$mice (Fig. $7 \mathrm{a}-\mathrm{c}$ ). Furthermore, oligomeric $A \beta_{42}$ was less efficient to reduce SC-CA1 EPSCs in $E f r 3 a^{+/-}$than in WT mice (Fig. $7 \mathrm{~d}-\mathrm{f}$ ) and no longer altered mEPSC frequency in CA1 pyramidal neurons (Fig. $7 \mathrm{~g}, \mathrm{~h}$ ) and PPF at the SC-CA1 synapse in Efr $3 a^{+/-}$mice (Fig. 7i, j). Halving Efr $3 a$ copy number restored the decreased mEPSC frequency in CA1 pyramidal neurons and the upregulated PPF at the SC-CA1 synapse in APP/PS1 mice (Supplementary Fig. 13). By contrast, oligomeric $A \beta_{42}$ caused a more robust inhibition of mEPSC frequency in CA1 pyramidal neurons in Efr3a overexpression mice (Supplementary Fig. 14). Taken together, these results indicate that reducing Efr $3 a$ is an effective method to inhibit $A \beta$-induced $\mathrm{PIP}_{2}$ depletion. Therefore, it is feasible to inhibit $\mathrm{A} \beta$-induced $\mathrm{PIP}_{2}$ hydrolysis region-specifically by creating conditional knockouts of Efr $3 a$ in the CA3 or CA1 area in mice.

We thus created conditional Efr $3 a$ knockouts in the CA3 and CA1 areas by crossing Efr3a-loxP mice to Grik4-cre and CamKIIa-cre mice, respectively (Fig. 8). In CA1-specific Efr3a conditional knockout (CA1-Efr3a cKO) mice 4-5 months of age (Fig. 8a) oligomeric $A \beta_{42}$ enhanced PPF at the SC-CA1 synapse
(Fig. 8b, c), implicating that deleting Efr3a at the postsynaptic site did not influence $A \beta$-induced Pr reduction. The minimal effect of deleting Efr $3 a$ in the CA1 area on $\mathrm{A} \beta$-induced inhibition of Pr at the SC-CA1 synapse was further confirmed by directly examining the RRP size and Pr using the repetitive stimulation protocol (Fig. 8d, e). In CA3-specific Efr3a conditional knockout (CA3Efr $3 a \mathrm{cKO}$ ) mice 4-5 months of age (Fig. 8f), however, oligomeric $\mathrm{A} \beta_{42}$ was no longer effective in increasing PPF (Fig. $8 \mathrm{~g}, \mathrm{~h}$ ) and inhibiting $\operatorname{Pr}$ (Fig. 8i, j) at the SC-CA1 synapse, indicating that knocking out $E f r 3 a$ at the presynaptic site rescued $\mathrm{A} \beta$-induced $\mathrm{Pr}$ decrease. We then investigated whether selectively deleting Efr3a in the CA1 or CA3 area in APP/PS1 mice regulated Pr at the SCCA1 synapse. In comparison to control mice, enhanced PPF (Fig. 8k, l) and decreased Pr (Fig. 8m, n) at the SC-CA1 synapse typical of 6-7-month-old APP/PS1 mice were still observed in age-matched APP/PS1 mice deleted for Efr $3 a$ in the CA1 area. In 6-7-month-old APP/PS1 mice deleted for Efr $3 a$ in the CA3 area, however, enhanced PPF and decreased Pr at the SC-CA1 synapse were restored to the control level (Fig. 8o-r). These results demonstrate that selectively deleting Efr $3 a$ at the presynaptic site of the SC-CA1 synapse effectively rescues the reduced Pr in APP/ PS1 mice. Taken together, these data prove that inhibiting A $\beta$ induced presynaptic $\mathrm{PIP}_{2}$ depletion efficaciously reduces $\mathrm{A} \beta$ induced Pr reduction.

The SC-CA1 synapse plays an essential role in learning and memory. Therefore, it will be interesting to explore whether lowering $A \beta$-induced presynaptic $\mathrm{PIP}_{2}$ depletion in the CA3 area improves the cognitive function in $\mathrm{AD}$. To this end, we first investigated whether $A \beta$-induced presynaptic defect affected long-term potentiation (LTP) at the SC-CA1 synapse in WT and Efr3a conditional knockout mice (Fig. 9). A high-frequency train stimulation ( 3 bursts of 20 pulses at $100 \mathrm{~Hz}$ separated by $1.5 \mathrm{~s}$ ) induced an apparent LTP of field excitatory postsynaptic potentials (fEPSPs) in WT mice (Fig. 9a-c), which had a robust presynaptic element as assessed by PPF (Fig. 9d-f) and was dramatically decreased in the presence of oligomeric $\mathrm{A} \beta_{42}$ (Fig. 9a-c). Blocking mGluR5 with MTEP or deleting Efr3a in CA 3 but not CA1 areas significantly ameliorated $A \beta$-induced LTP impairment (Fig. 9a-c), accompanying a decreased PPF following LTP induction (Fig. 9d-f). These results indicate that decreasing presynaptic GPCR responsiveness prevents oligomeric $\mathrm{A} \beta_{42}$-induced LTP impairment.

We next studied if deleting Efr $3 a$ in the CA3 area ameliorated LTP impairment and improved cognitive function in APP/PS1 mice. As expected, the high-frequency train stimulation induced a dramatically decreased LTP in 6-7-month-old APP/PS1 mice in comparison to WT animals of the same age (Fig. 10a-c). Deleting Efr $3 a$ in the CA3 but not in the CA1 area significantly restored the diminished LTP in APP/PS1 mice (Fig. 10a-c). These data 
a
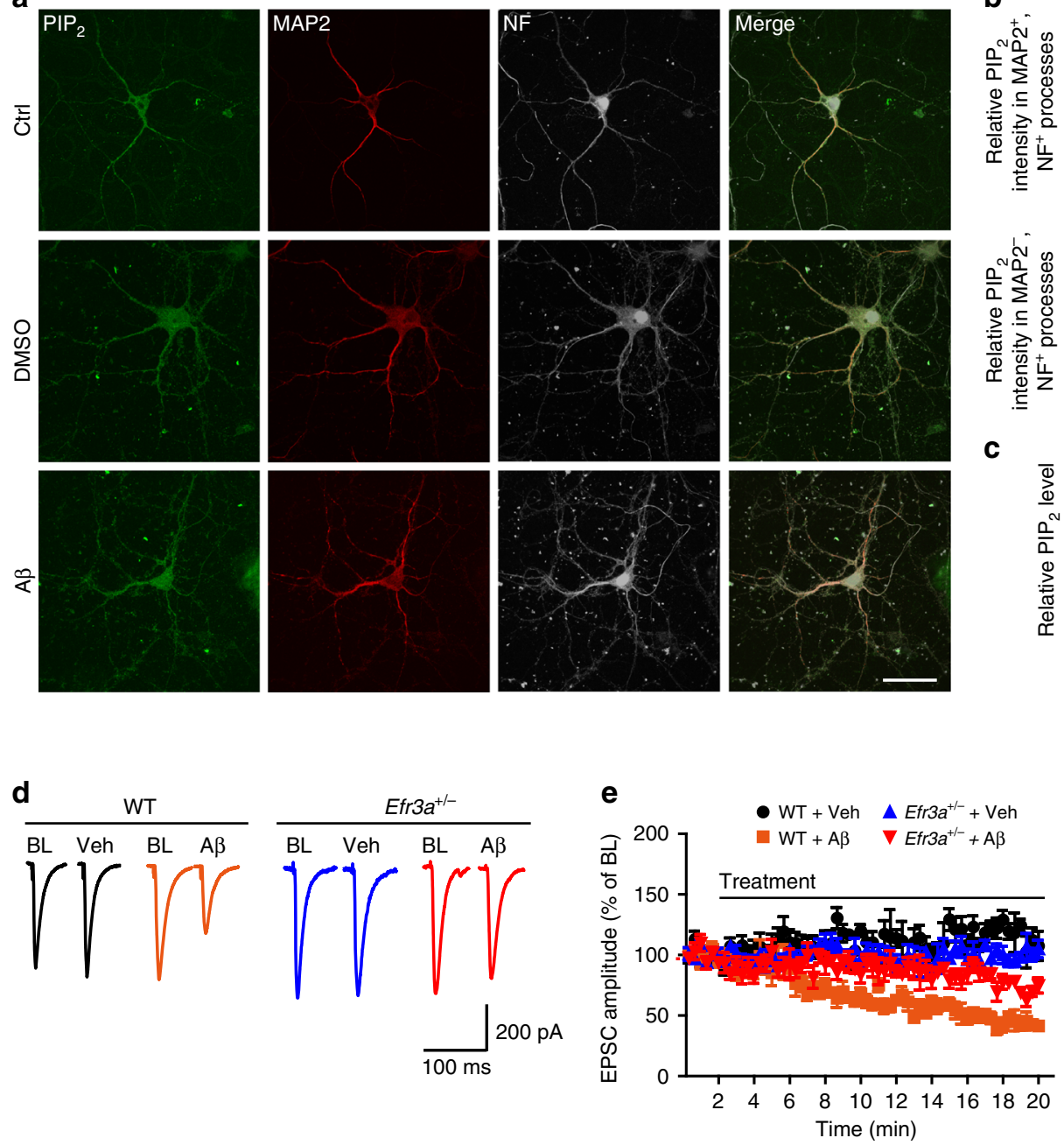

g

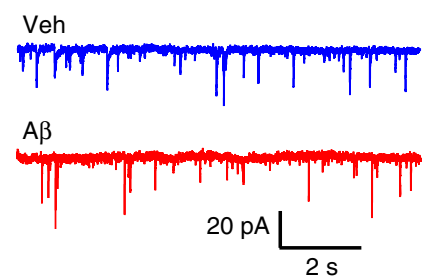

h

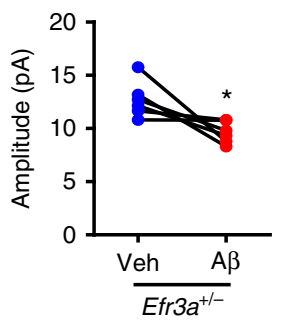

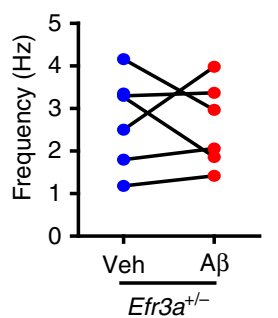

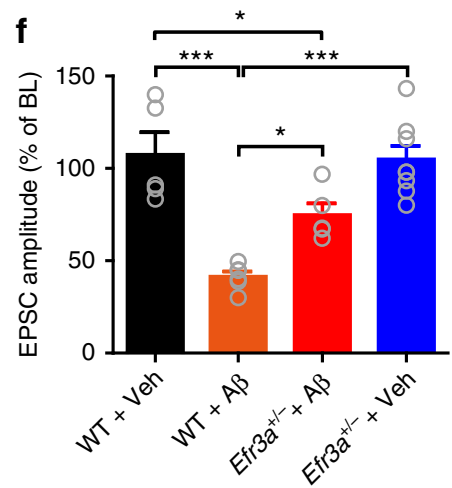

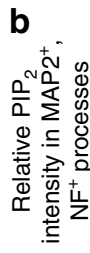
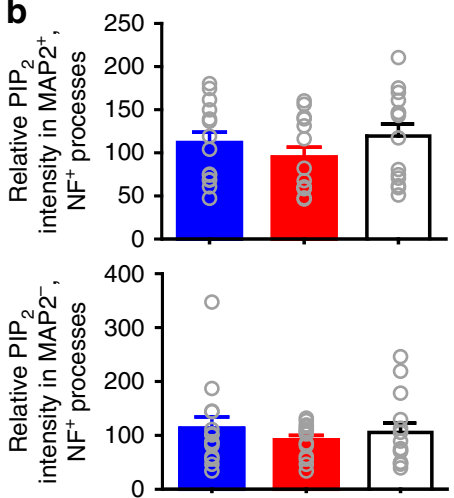

C
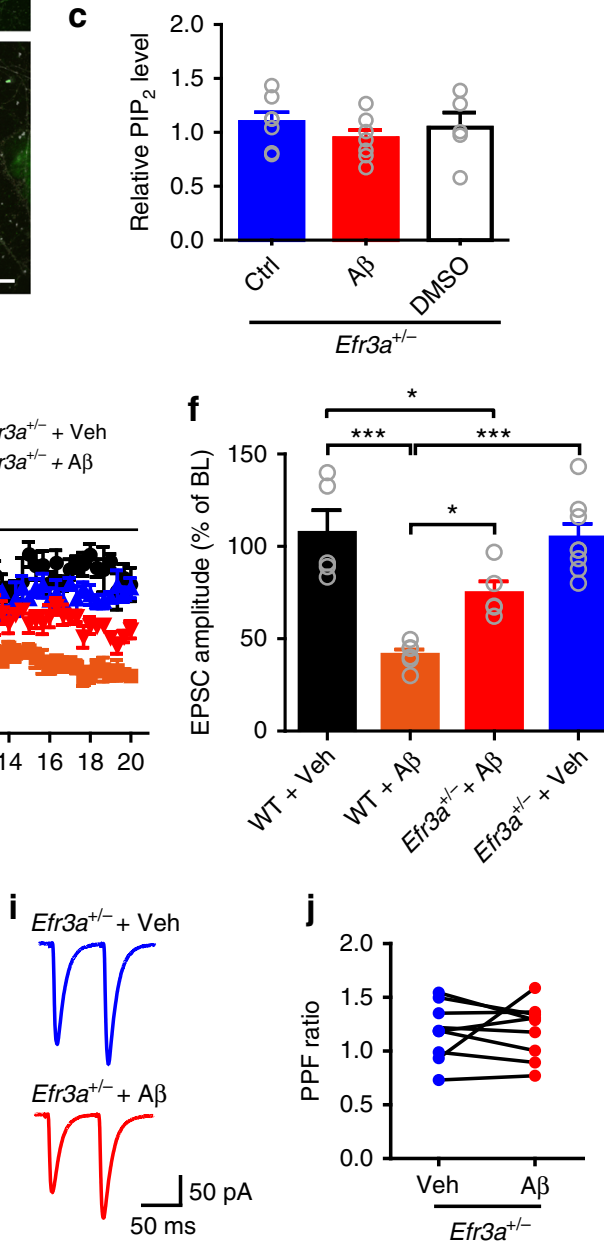

Fig. 7 Oligomeric $A \beta$-induced $\mathrm{PIP}_{2}$ reduction and presynaptic deficit are rescued by knocking down Efr3a. a Confocal images showing the effect of oligomeric $A \beta$ on $\mathrm{PIP}_{2}$ levels in neuronal processes in primary hippocampal neurons from $E f r 3 a^{+/-}$mice. Bar, $50 \mu \mathrm{m}$. $\mathbf{b}$ Quantification of relative PIP 2 intensity in dendrites (upper panel) and axons (bottom panel) showing knocking down Efr3a prevents A $\beta$-induced suppression of PIP 2 in neurites. One-way ANOVA with post hoc Dunnett's test; $F_{(2,39)}=0.98$ (upper); $F_{(2,49)}=0.44$ (bottom); $P>0.05 ; N=14$ per group. c Quantitative results showing knocking down Efr3a prevents $A \beta$-induced suppression of $\mathrm{PIP}_{2}$ in cultured hippocampal neurons (measured by $\mathrm{PIP}_{2}$ ELISA). One-way ANOVA with post hoc Dunnett's test; $F_{(2,16)}=0.66 ; P>0.05 ; N=5-7$ per group. $\mathbf{d}$, e Representative traces (d) and the time course of normalized amplitude (e) of SC-CA1 EPSCs in WT and $E f r 3 a^{+/-}$hippocampal slices before (BL) and after drug treatment (Veh or A $\beta$ ). $\mathbf{f}$ Bar graph representing the relative magnitude of EPSCs recorded in the last $1 \mathrm{~min}$ of drug treatment shown in e. One-way ANOVA with post hoc Dunnett's test; $F_{(3,23)}=16.88 ;{ }^{\star} P<0.05 ;{ }^{\star \star \star \star} P<0.001 ; N=5-8$ per group. $\mathbf{g}, \mathbf{h}$ Representative traces ( $\mathbf{g}$ ) and quantification (h) of mean values of the amplitude (left) and frequency (right) of mEPSCs in CA1 pyramidal neurons in $E f r 3 a^{+/}$- mice showing oligomeric $A \beta$ treatment no longer inhibits mEPSC frequency. $t$ test; ${ }^{\star} P<0.05 ; N=6$ per group. $\mathbf{i}, \mathbf{j}$ Representative traces (i) and quantification (j) of PPF of SC-CA1 EPSCs showing oligomeric A $\beta$ does not alter PPF ratio in Efr3a ${ }^{+/-}$mice. $t$ test; $P>0.05 ; N=9$ per group. Data are mean \pm SEM. Source data are provided as a Source Data file 
a

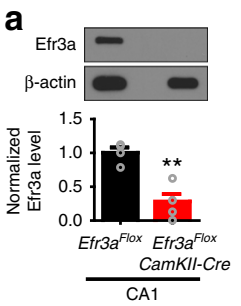

f

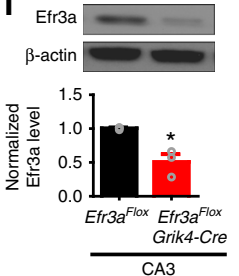

k

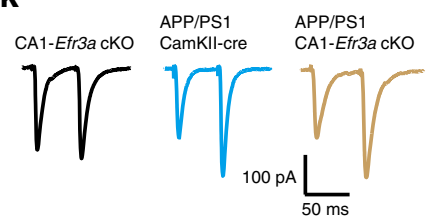

O

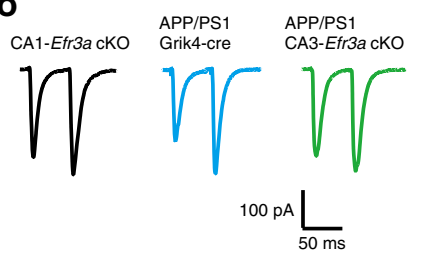

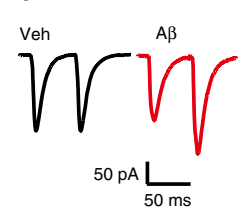

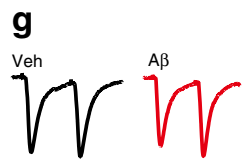

$50 \mathrm{pA} \underset{50 \mathrm{~ms}}{\mathrm{~L}}$
C
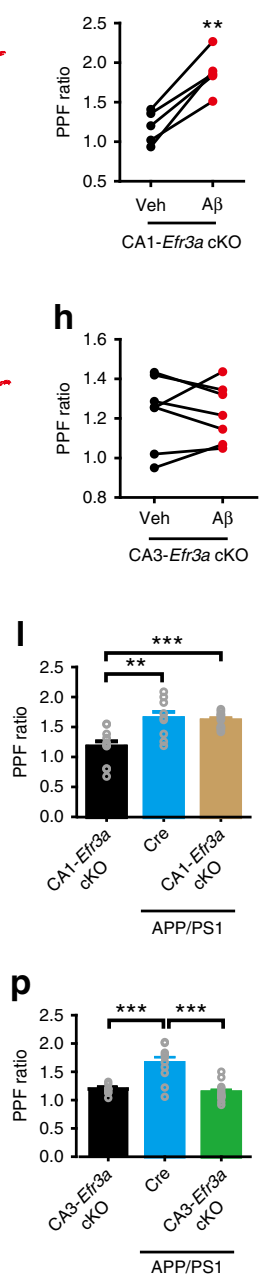

d

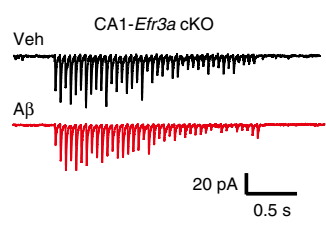

i

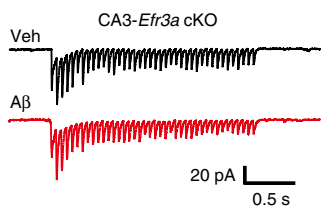

m

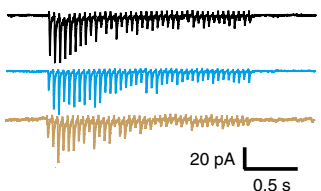

q

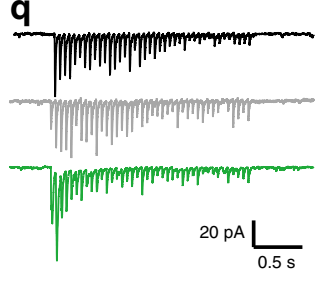

e
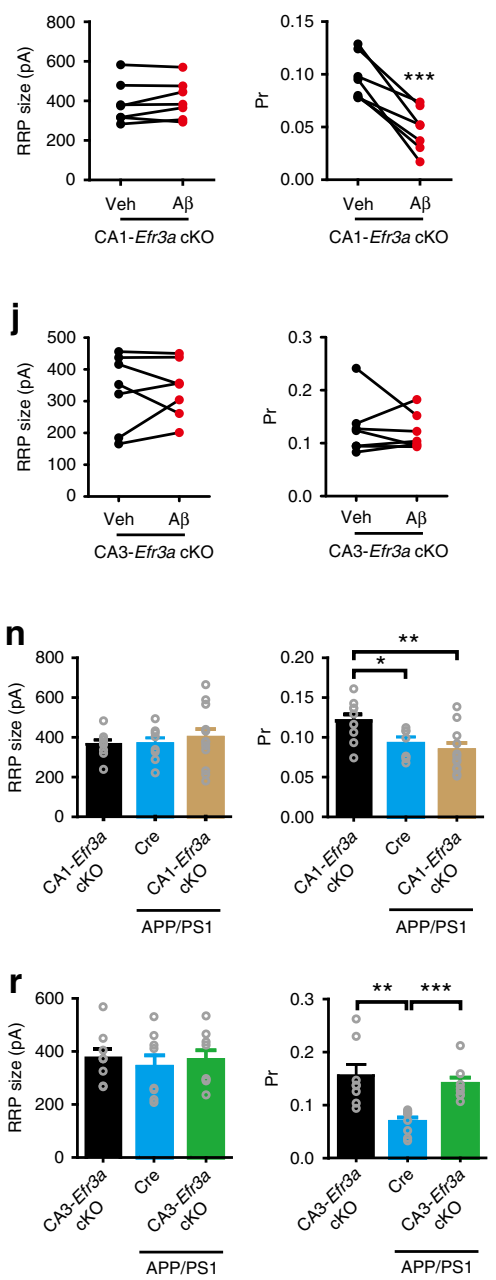

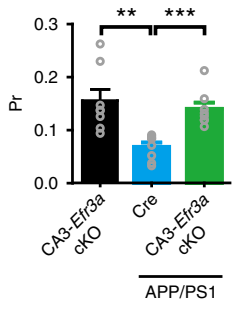

Fig. 8 Selectively knocking out Efr3a in the CA3 area prevents oligomeric A $\beta$-induced inhibition of presynaptic release probability at the SC-CA1 synapse. a-j Representative traces of PPF (b, CA1-Efr3a cKO mice; $\mathbf{g}$, CA3-Efr3a cKO mice) and $20 \mathrm{~Hz}$ train responses (d, CA1-Efr3a cKO mice; $\mathbf{i}$, CA3-Efr3a cKO mice) and quantification of PPF ratio (c, CA1-Efr3a cKO mice; $\mathbf{h}$, CA3-Efr3a cKO mice), RRP size (e, CA1-Efr3a cKO mice; $\mathbf{j}$, CA3-Efr3a cKO mice; left), and Pr (e, CA1-Efr3a cKO mice; j, CA3-Efr3a cKO mice; right) at the SC-CA1 synapse showing oligomeric A 3 (400 nM) increases Pr in CA1-Efr3a cKO mice (immunoblotting and quantification of Efr3a in CA1 shown in $\mathbf{a}$ ), whereas oligomeric $A \beta$ no longer changes $\operatorname{Pr}$ in CA3-Efr3a cKO mice (immunoblotting and quantification of Efr3a in CA3 shown in $\mathbf{f}$ ). $t$ test; ${ }^{\star} P<0.05$; ${ }^{\star \star} P<0.01$; ${ }^{\star \star \star} P<0.001 ; N=3-7$ per group. $\mathbf{k}-\mathbf{r}$ Representative traces of PPF (k, APP/PS1 CA1Efr3a cKO and control mice; $\mathbf{0}$, APP/PS1 CA3-Efr3a cKO and control mice) and $20 \mathrm{~Hz}$ train responses (m, APP/PS1 CA1-Efr3a cKO and control mice; q, APP/PS1 CA3-Efr3a cKO and control mice) and quantification of PPF ratio (I, APP/PS1 CA1-Efr3a cKO and control mice; $\mathbf{p}$, APP/PS1 CA3-Efr3a cKO and mice), RRP size (n, APP/PS1 CA1-Efr3a cKO and control mice; $\mathbf{r}$, APP/PS1 CA3-Efr3a cKO and control mice; left), and Pr (n, APP/PS1 CA1-Efr3a cKO and control mice; $\mathbf{r}$, APP/PS1 CA3-Efr3a cKO and mice; right) at the SC-CA1 synapse showing selectively knocking out Efr3a in the CA3 area restores the decreased Pr in APP/PS1 mice. One-way ANOVA with post hoc Dunnett's test; $F_{(2,29)}=11.38(\mathbf{I}) ; F_{(2,31)}=20.66(\mathbf{p}) ; F_{(2,26)}=0.28(\mathbf{n}$, left $) ; F_{(2,26)}=5.99$ $\left(\mathbf{n}\right.$, right); $F_{(2,21)}=0.986$ (r, left); $F_{(2,21)}=0.19$ (r, right); ${ }^{\star} P<0.05 ;{ }^{\star \star} P<0.01 ;{ }^{\star \star \star} P<0.001 ; N=8-15$ per group. Data are mean $\pm S E M$. Source data are provided as a Source Data file

indicate that selectively knocking out presynaptic Efr3a enhanced the SC-CA1 synapse plasticity in APP/PS1 mice, suggesting that decreasing the presynaptic GPCR sensitivity may improve the cognitive function of APP/PS1 mice. By comparing the performance of 6-7-month-old APP/PS1 mice in the Morris water maze (MWM) task to that of age-matched WT animals, we were able to reliably separate APP/PS1 mice from their WT controls in the escape latency and target time plots (Fig. 10d, e). Deleting Efr $3 a$ in the CA3 but not in the CA1 area in 6-7-monthold APP/PS1 mice significantly shortened the escape latency and increased the time spent in the target quadrant to the levels of WT mice in the MWM test (Fig. 10d, e). These results implicate that deleting Efr $3 a$ in the CA3 area improves spatial learning and memory in APP/PS1 mice.

\section{Discussion}

Our work demonstrates a key presynaptic target of pathogenic $A \beta$ in early $\mathrm{AD}$ and clarify $\mathrm{A} \beta$-induced depletion of $\mathrm{PIP}_{2}$ underlies $\operatorname{Pr}$ reduction at an excitatory synapse in the hippocampus. $\mathrm{A} \beta$-induced activation of presynaptic mGluR5 depletes membrane $\mathrm{PIP}_{2}$ in axons, which in turn disrupts neurotransmitter release. Notably, reducing $\mathrm{A} \beta$-induced $\mathrm{PIP}_{2}$ depletion in the CA3 area augments release $\mathrm{Pr}$ at the SC-CA1 synapse and enhances spatial learning and memory in APP/PS1 mice. As this $\mathrm{A} \beta$-induced $\operatorname{Pr}$ reduction precedes synapse and neuronal loss, controlling the CA3 $\mathrm{PIP}_{2}$ level may become an effective way of preventing $\mathrm{AD}$ progression.

We found that reduced mEPSC frequency in CA1 pyramidal neurons was a robust hallmark in 6-7-month-old APP/PS1 mice. 
a

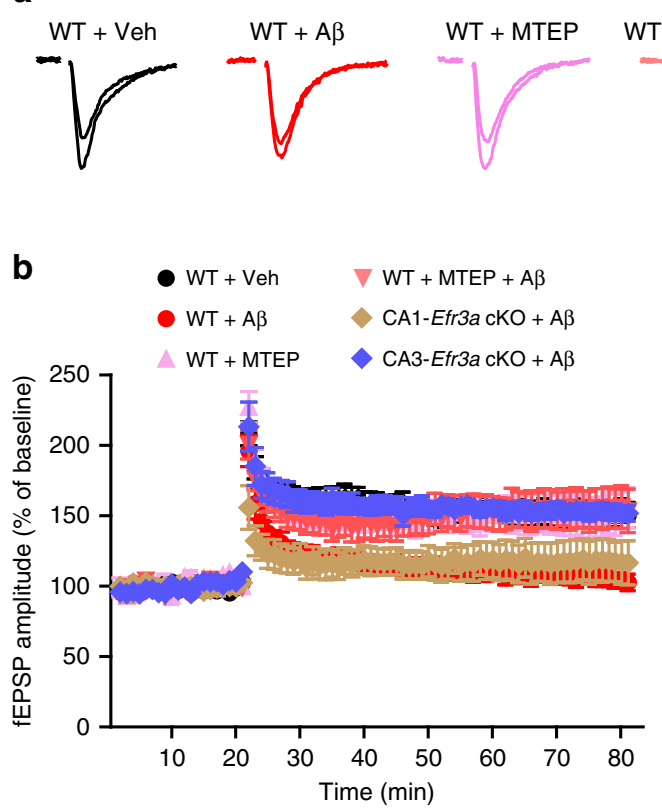

CA1-Efr3a cKO CA3-Efr3a cKO

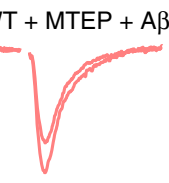

$+A \beta$
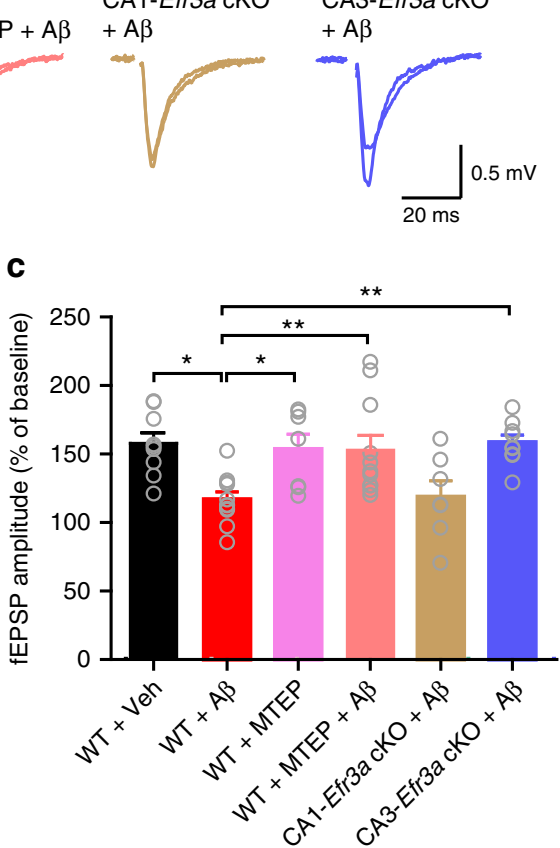

d
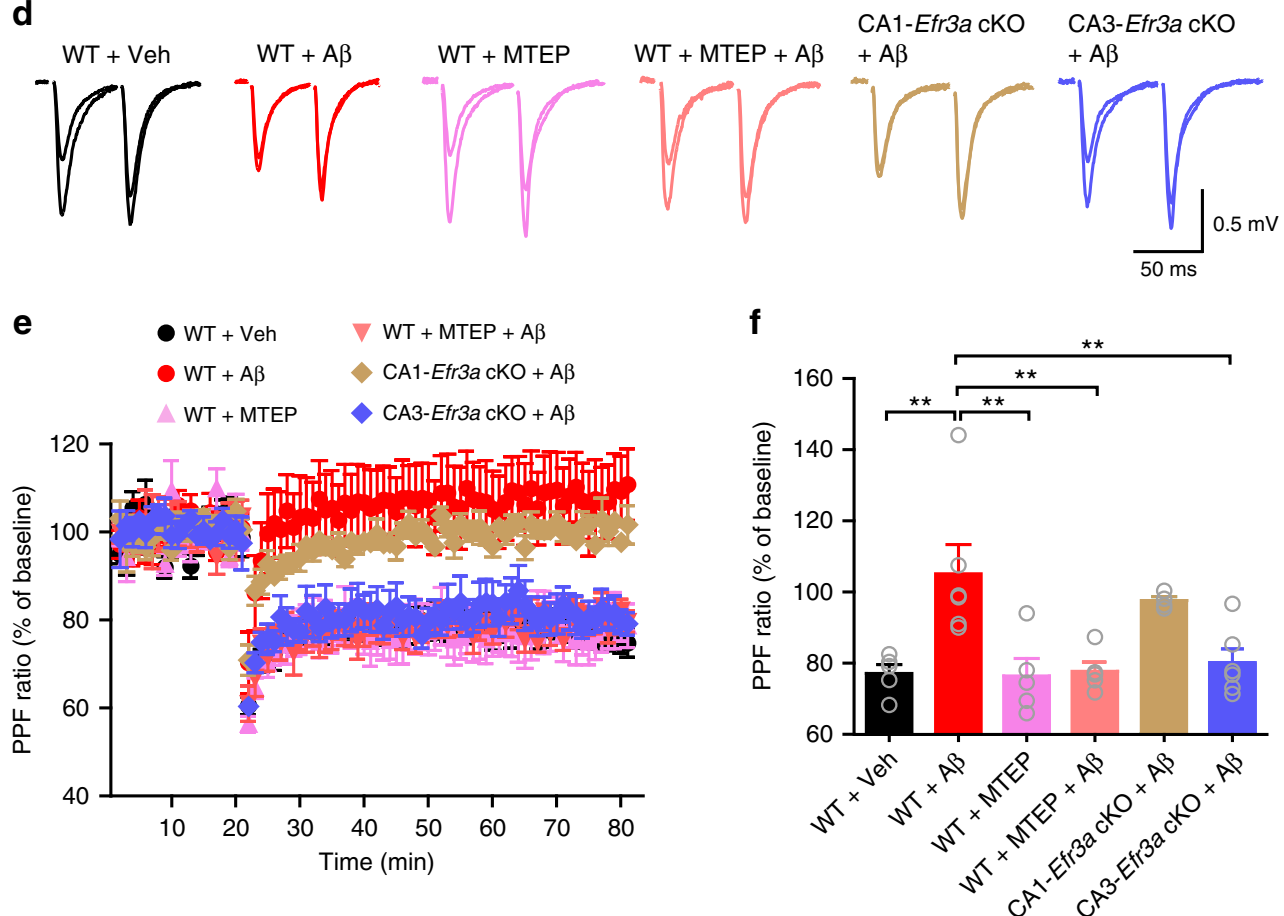

Fig. 9 Blocking mGluR5 with MTEP or selectively knocking out Efr3a in the CA3 area ameliorates oligomeric A $\beta$-induced impairment of a presynapticallyexpressed LTP at the SC-CA1 synapse. a Representative traces showing averaged fEPSPs recorded in CA1 area 10 min before and 50 min after highfrequency SC stimulation (superimposed) in WT slices treated with vehicle (WT + Veh), oligomeric A $\beta(W T+A \beta), M T E P(W T+M T E P)$, or both MTEP and oligomeric $A \beta(W T+M T E P+A \beta)$, or in oligomeric $A \beta$-treated hippocampal slices from mice selectively knocking out Efr3a in the CA1 (CA1-Efr3a cKO $+A \beta$ ) or CA3 (CA3-Efr3a CKO $+A \beta$ ) area. $\mathbf{b}$ The time course of the normalized amplitude of fEPSPs before and after an LTP induction protocol in conditions shown in a. c Bar graph representing mean LTP magnitude 50 min after LTP induction shown in b. One-way ANOVA with post hoc Dunnett's test; $F_{(5,48)}=5.171 ;{ }^{\star} P<0.05 ;{ }^{\star \star} P<0.01 ; N=7-11$ per group. $\mathbf{d}$ Representative traces of PPF of fEPSPs recorded in the CA1 area 10 min before and 50 min after high-frequency SC stimulation in the same conditions as in $\mathbf{a}$. e The time course of the normalized PPF ratio before and after an LTP induction in the same conditions as in d. f Bar graph showing the relative PPF ratio before and after an LTP protocol. One-way ANOVA with post hoc Dunnett's test; $F_{(5,25)}=6.361 ;{ }^{\star \star} P<0.01 ; N=4-6$ per groups. Data are mean \pm SEM. Source data are provided as a Source Data file 
a

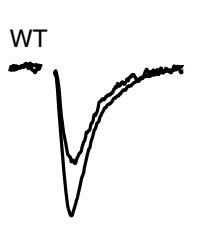

b
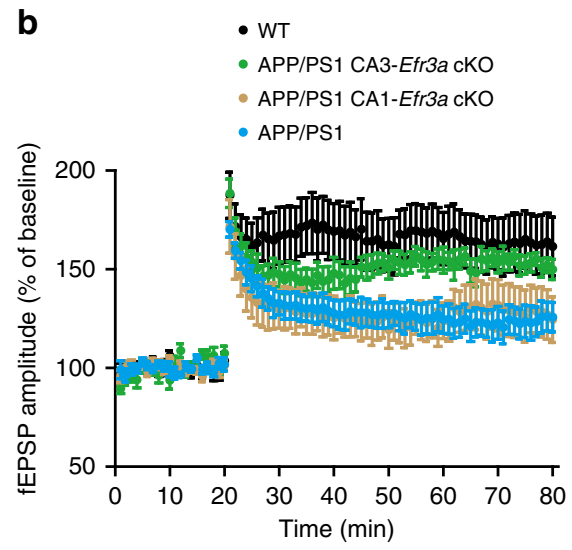

d

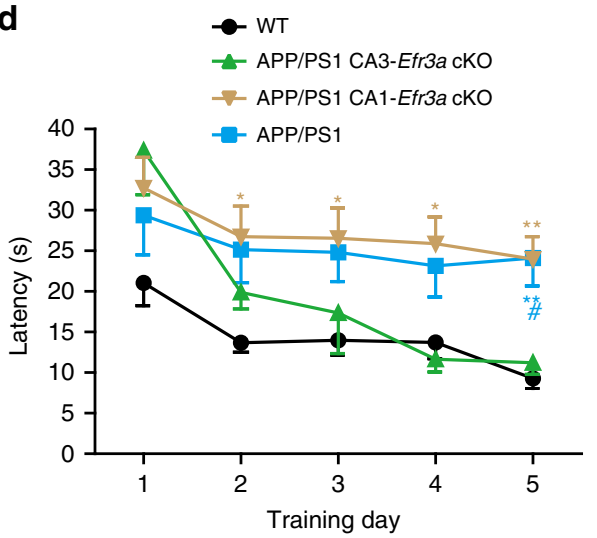

APP/PS1 APP/PS1

CA3-Efr3a cKO CA1-Efr3a cKO
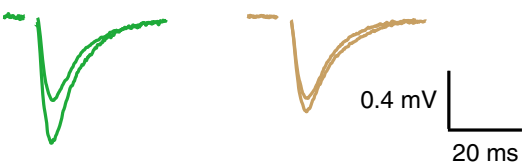

C

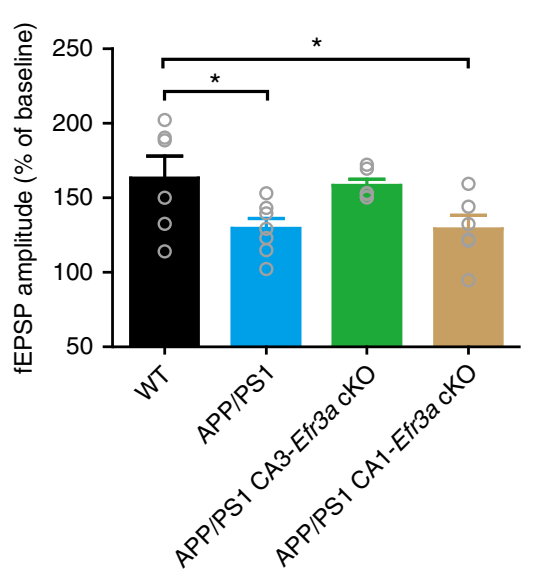

e

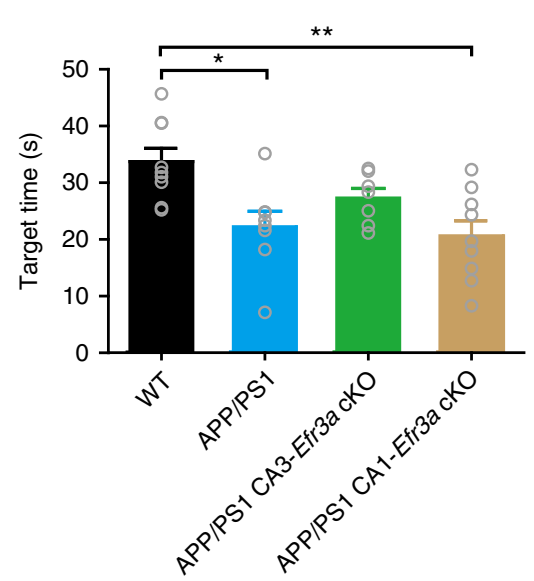

Fig. 10 Selectively knocking out Efr3a in the CA3 area ameliorates impairment in a presynaptically-expressed LTP at the SC-CA1 synapse and spatial learning and memory deficits in APP/PS1 mice. a Representative traces of averaged fEPSPs recorded in the CA1 area 10 min before and 50 min after highfrequency SC stimulation (superimposed) in WT, APP/PS1, APP/PS1 CA1-Efr3a cKO, and APP/PS1 CA3-Efr3a cKO mice. b Summary time course of the normalized amplitude of fEPSPs recorded from WT, APP/PS1, APP/PS1 CA1-Efr3a cKO, and APP/PS1 CA3-Efr3a cKO mice during an LTP protocol. c Bar graph representing mean LTP magnitude recorded 50 min after LTP induction shown in b. One-way ANOVA with post hoc Dunnett's test;

$F_{(3,21)}=3.87 ;{ }^{\star} P<0.05 ; N=6-7$ per group. $\mathbf{d}$ Quantification of the escape latency in each session of the hidden-platform test for WT, APP/PS1, APP/PS1 CA1-Efr3a cKO, and APP/PS1 CA3-Efr3a cKO mice. Two-way ANOVA with post hoc Bonferroni test; animal, $F_{(3,145)}=15.78, P<0.001$; training session, $F_{(4,145)}=9.51, P<0.001 ;{ }^{\# P}<0.05$ (APP/PS1 CA3-Efr3a cKO vs. APP/PS1); ${ }^{*} P<0.05 ;{ }^{\star \star} P<0.01$ (blue *, WT vs. APP/PS1; brown *, WT vs. APP/PS1 CA1Efr3a CKO); $N=7-9$ per group. e Bar graph showing the mean target quadrant searching time in the probe test for WT, APP/PS1, APP/PS1 CA1-Efr3a cKO, and APP/PS1 CA3-Efr3a cKO mice. One-way ANOVA with post hoc Dunnett's test; $F(3,29)=6.13 ;{ }^{\star} P<0.05 ;{ }^{\star \star} P<0.01 ; N=7-9$ per groups. Data are mean \pm SEM. Source data are provided as a Source Data file

CA1 pyramidal neurons mainly receive excitatory inputs from CA3 pyramidal neurons and layer III pyramidal neurons in the entorhinal cortex. Thus, $A \beta$-induced changes in mEPSC frequency in CA1 pyramidal neurons may be attributed to presynaptic alterations in both glutamatergic terminals forming synapses on CA1 pyramidal neurons. Although we are not able to rule out the involvement of the excitatory inputs from the entorhinal cortex completely, the decrease in mEPSC frequency may primary be associated with $\mathrm{A} \beta$-induced suppression of glutamate release from the SC. Reducing the $A \beta$ sensitivity in
CA3 pyramidal neurons not only increased the amplitude of SC-CA1 EPSCs but also restored the diminished mEPSC frequency in CA1 pyramidal neurons (Supplementary Fig. 15). Because both areas CA3 and CA1 are critical in encoding memory sequences, our results implicate that reduced glutamate release at the SC-CA1 synapse represents a crucial early event leading to cognitive decline in $\mathrm{AD}$.

Our results showed that $400 \mathrm{nM}$ oligomeric $\mathrm{A} \beta_{42}$ reduced glutamate release from the SC in WT mice to a level similar to that in 6-7-month-old APP/PS1 and 4-month-old 5xFAD mice. 
In another $\mathrm{APP} / \mathrm{PS} 1$ transgenic line $\mathrm{APP}_{\mathrm{Swe}} / \mathrm{PS} 1_{\mathrm{M} 146 \mathrm{~L}}$, however, there is no reduction in $\operatorname{Pr}^{49}$. One possible explanation is that the effective concentration of oligomeric $A \beta$ has to rise significantly at the target synapse to suppress $\mathrm{Pr}$ in early AD. Although in no way could we fully determine the effective concentration of locally distributed soluble $A \beta$, the concentration of the most toxic oligomeric $A \beta_{42}$ has to rise to hundreds of nanomolar level to inhibit Pr. A moderate increase of $A \beta$ to the picomolar level ${ }^{19}$, or even 25 -fold increase of $A \beta_{42}$ found in 4-month-old APP/PS1 mice ${ }^{50}$, usually cause an increase in Pr at the SC-CA1 synapse, leading to enhanced basal synaptic transmission ${ }^{19}$ that we also observed with $20 \mathrm{nM}$ oligomeric $A \beta_{42}$. A moderate increase in intracellular $A \beta$ oligomers can also increase evoked responses by $\mathrm{Ca}^{2+}$-dependent insertion of GluAl subunits ${ }^{51}$. A further increase in $A \beta$ oligomers to the low micromolar level, however, induces mostly postsynaptic depression and loss of dendritic spines ${ }^{8,9}$. Thus, although we are not in a position to define what the pathological level of oligomeric $A \beta$ is ${ }^{8}$, we believe the early presynaptic deficit in $\mathrm{AD}$ requires elevation of soluble $\mathrm{A} \beta$ at least in the high nanomolar range. On the other hand, the facilitating effect of small increases in $A \beta$ within a physiological range on presynaptic neurotransmitter release represents a physiological function of oligomeric $A \beta^{19}$.

The probability of neurotransmitter release is tightly associated with $\mathrm{Ca}^{2+}$-dependent synaptic vesicle fusion in the presynaptic terminal. In contrast to enhancing Pr by physiological range of $A \beta$ via increasing presynaptic $\mathrm{Ca}^{2+}$, our results implicate that high nanomolar $A \beta$ mainly suppresses $\mathrm{Pr}$ via reducing $\mathrm{PIP}_{2^{-}}$ dependent presynaptic vesicle fusion. In cultured neurons, $200 \mathrm{nM} \mathrm{A} \beta$ can also enhance $\mathrm{Pr}^{42}$, suggesting that $A \beta$ may interfere with presynaptic function in a $\mathrm{PIP}_{2}$-independent manner. However, $A \beta$-induced Pr suppression may not be apparent in other central synapses (e.g., the recurrent inputs to CA3 pyramidal neurons $)^{52}$. It will be interesting to investigate if these synapses lack such a mechanism or a compensatory process engages following $A \beta$ accumulation in future studies. Reduced Pr exists in other $\mathrm{AD}$ models. Conditionally knocking out presenilins 1 and 2 in CA3 pyramidal neurons significantly inhibited $\mathrm{Ca}^{2+}$ release from ryanodine receptors, thus reducing $\mathrm{Pr}$ at the SC-CA1 synapse $\mathrm{e}^{53}$. Our results established that maintaining the membrane $\mathrm{PIP}_{2}$ at a relatively high level in axons is critical in preserving a proper $\mathrm{Pr}$ (Fig. 4). A low $\mathrm{PIP}_{2}$ level in the brain is a hallmark for both aging and $\mathrm{AD}$ animals ${ }^{38,54}$. However, in normal aging mice $\mathrm{Pr}$ is not altered. This could be due to a greater $\mathrm{PIP}_{2}$ hydrolysis initiated by oligomeric $A \beta$ in $\mathrm{AD}$ than that in normal aging animals with a low PLC expression level ${ }^{55}$. PIP 2 interacts with synaptotagmin 1 and Munc13-2 46,56 to control exocytosis. Future studies are required to address the detailed mechanism underlying $\mathrm{PIP}_{2}$-dependent $\mathrm{Pr}$ regulation in $\mathrm{AD}$.

One of the major findings of our study is that inhibiting mGluR5 rescued the presynaptic deficit in early AD. Genetically deleting ${ }^{36}$ or pharmacologically inhibiting ${ }^{35,37}$ mGluR5 has been shown to significantly improve cognitive impairment in $\mathrm{AD}$ mice, as mGluR5 may function as an $A \beta$ receptor or co-receptor with $\mathrm{PrPC}^{\mathrm{C}}$ in both APP overexpression and knock-in mouse models of $\mathrm{AD}^{32-34}$. Our results clearly show that presynaptic mGluR5mediated $\mathrm{PIP}_{2}$ hydrolysis requires $\mathrm{PrPC}^{\mathrm{C}}$ as well. Although group I mGluRs are expressed in both presynaptic and postsynaptic loci ${ }^{57}$, mGluR5 density is higher in dendrites than in axons (Fig. 6a, b). However, high nanomolar A $\beta$ oligomers deplete PIP $_{2}$ to a greater level in axons than in dendrites. Although we do not know exactly what causes this differentially regulation of $\mathrm{PIP}_{2}$ in neurites, we nevertheless speculate that this may be due to a combination of enhanced mGluR5 receptor responsiveness and downstream process efficacy in axons.
Functionally, we believe presynaptic mGluR5 may be a main target of soluble $A \beta$ in early $\mathrm{AD}$ based on the following observations, although postsynaptic mGluR5 has been shown to be involved in A $\beta$-induced suppression of LTP and enhancement of LTD $^{29,30,58}$. First, blocking mGluR5 did not restore nanomolar oligomeric $A \beta_{42}$-induced suppression of mEPSC amplitude, implicating that activation of postsynaptic mGluR5 is not involved in the oligomeric $\mathrm{A} \beta$-induced mild postsynaptic defect. Although the detailed mechanisms require further examination, removal of surface AMPA and NMDA receptors may account for this oligomeric $A \beta$-induced reduction of mEPSC amplitude ${ }^{58,59}$. On the other hand, micromolar oligomeric $A \beta$ induce mature spine loss via mGluR5-mediated downregulation of CaMKII activity in the postsynaptic site in APP knock-in mouse model of $\mathrm{AD}^{60}$. Second, selectively decreasing the sensitivity of presynaptic GPCRs ameliorated oligomeric A $\beta$-induced suppression of $\operatorname{Pr}$ and a form of LTP with a notable presynaptic element, thus ruling out indirect presynaptic effects due to activation of postsynaptic mGluR5. A presynaptically-expressed SC-CA1 LTP can be induced by $200 \mathrm{~Hz}^{61,62}$ or multiple trains of $100 \mathrm{~Hz}^{63,64}$ tetanus and may require postsynaptically-activated $\mathrm{Ca}^{2+}$ influx through L-type calcium channels and NMDA receptors ${ }^{61,62}$. Although we do not know the postsynaptic mechanism underlying this presynaptically-expressed LTP, our results establish that $A \beta$ oligomers suppress this LTP through presynaptic mGluR5.

In the current study, we controlled membrane $\mathrm{PIP}_{2}$ hydrolysis by manipulating the Efr3a level. It has long been known that Efr3a functions as an adaptor in the type IIIa phosphatidylinositol 4-kinase (PI4KIIIa) complex ${ }^{65,66}$. Although PI4KIIIa is responsible for generating phosphatidylinositol 4-phosphate (PI4P), the precursor of PIP $_{2}$, reducing Efr3a or PI4KIIIa induces minimal changes in the membrane $\mathrm{PIP}_{2}$ level ${ }^{65,66}$. Knocking out the type $1 \gamma$ phosphatidylinositol phosphate kinase, the main enzyme responsible for $\mathrm{PIP}_{2}$ synthesis at synapses, however, significantly depletes membrane $\mathrm{PIP}_{2}$, leading to decreased transmitter release ${ }^{67}$. Efr3a may also control the responsiveness of other GPCRs that are putative $A \beta$ receptors such as the type- 1 angiotensin II receptor ${ }^{48}$. Thus, controlling the expression level of Efr3a may regulate a series of GPCRs that are targets of $A \beta$, though we believe mGluR5 is the main target of pathological level of $A \beta$. Nevertheless, antagonizing Efr $3 \mathrm{a}^{68}$ may provide a more robust way to treat $\mathrm{AD}$ rather than targeting only one type of GPCR.

\section{Methods}

Animals. All procedures were carried out in accordance with the National Institutes of Health Guidelines for the Care and Use of Laboratory Animals and were approved by the Animal Advisory Committee at Zhejiang University. B6, APP/PS1 double-transgenic, 5xFAD, M146V, Grik4-cre, and Camk2a-creERT2 mice were purchased from The Jackson Laboratory (Bar Harbor, ME). Efr3a double-flox $\left(E f r 3 a^{f / f}\right), E f r 3 a^{+l-}$ heterozygotes, Efr3af/f-Grik4-cre, Efr3af/f-Camk2a-creERT2, APP/PS1-Efr3af/f-Grik4-cre, APP/PS1-Grik4-cre, APP/PS1-Efr3af/f-Camk2acreERT2, and APP/PS1-Camk2a-creERT2 animals were obtained by heterozygous mating. Tamoxifen was intraperitoneally (i.p.) injected once a day for 5 consecutive days at a dose of $100 \mathrm{mg} \mathrm{kg}^{-1}$ to induce cre recombinase expression in the creER lines. For behavioral experiments, only male mice were used. The mouse genotypes were identified by PCR using genomic DNA from mouse tails and embryo tissues Primers and detailed protocols are available in the Supplementary Table 1 and Supplementary Methods. LY-411575 was used to inhibit $\gamma$-secretase. The protocols of LY-411575 preparation and treatment are detailed in Supplementary Table 2 and Supplementary Methods.

Antibodies and drugs. The following commercially available antibodies were used: rabbit anti-amyloid precursor protein, C-terminal fragments (anti-CTFs), purified mouse anti- $\beta$-Amyloid, 1-16 (6E10), rabbit anti-Efr3a, mouse anti-PLC $\beta 1, \mathrm{D}-8$, mouse anti-PLC $\beta 4$, A- 8 , mouse anti- $\beta$-actin, and HRP-conjugated secondary antibodies were used in Western blotting; mouse anti-PIP ${ }_{2}$ antibody, chicken antineurofilament-L (anti-NF), rabbit anti-MAP2 antibody, rabbit anti-mGluR5 (extracellular), mouse anti-MAP2, purified anti-CD230 (Prion) antibody, and Alexa Fluor-conjugated secondary antibodies (488 donkey anti-rabbit, 546 donkey 
anti-mouse, 546 donkey anti-rabbit, 405 goat anti-rabbit IgG H\&L, 488 goat antimouse IgM mu chain and 647 goat anti-chicken IgY H\&L) were used in immunocytochemistry. The antibody information is detailed in Supplementary Methods.

Tamoxifen was dissolved in $100 \%$ ethanol; $\mathrm{PI}(4,5) \mathrm{P}_{2} \mathrm{diC} 8$ was dissolved in the electrode solution; DHPG, MTEP, and U73122 were dissolved in the bath solution or culture medium. The final concentrations of DMSO did not exceed $0.1 \%$ throughout the study. The protocol of oligomeric $A \beta_{42}$ preparation and drug information are detailed in Supplementary Table 2 and Supplementary Methods.

Golgi staining. Golgi staining was carried out using an FD Rapid GolgiStain Kit according to the manufacturer's instructions (see details in Supplementary Methods).

Slice recording. Briefly, mice (4- or 6-7-month-old) were anesthetized with isoflurane and decapitated, and transverse slices of hippocampus $(300 \mu \mathrm{m}$ for wholecell recording or $350 \mu \mathrm{m}$ for fEPSP recording) were cut with a tissue slicer (VT 1200S, Leica) in oxygenated ACSF (for whole-cell recording) or in oxygenated cutting solutions (for fEPSP recording). Whole-cell recordings were performed on CA1 pyramidal neurons ${ }^{69,70}$. mEPSCs signals were recorded at $-70 \mathrm{mV}$ in ACSF containing $0.5 \mu \mathrm{M}$ tetrodotoxin (TTX) and $10 \mu \mathrm{M}$ bicuculline. Evoked EPSCs were elicited in the presence of $10 \mu \mathrm{M}$ bicuculline using a bipolar stimulating electrode placed in stratum radiatum $300 \mu \mathrm{m}$ away from the recording site. PPF experiments were carried out by delivering a pair of stimuli with an interval of $50 \mathrm{~ms}$. To estimate the RRP size and release $\mathrm{Pr}$, a repeated $20 \mathrm{~Hz}$ train stimulation protocol was used to evoke 40 EPSCs. The RRP size was calculated by linear interpolating the linear portion of the cumulative EPSC amplitude plot to virtual stimulus 0 . The release Pr was calculated as the mean amplitude of the 1st EPSC during the repeated train stimulations divided by the RRP size. fEPSPs were elicited by stimulating the SC and recording with a borosilicate glass electrode filled with ACSF placed in CA1 stratum radiatum. LTP was induced by 3 bursts of 20 pulses at 100 $\mathrm{Hz}$ separated by $1.5 \mathrm{~s}$. Detailed protocols are available in Supplementary Methods.

Cell culture. Primary hippocampal neuron cultures were prepared from embryonic day 18 (E18) mice ${ }^{69}$. Briefly, embryos were removed from maternal mice anesthetized with isoflurane and euthanized by decapitation. Hippocampi were dissected in HBSS, followed by a digestion with $0.25 \% \mathrm{w} / \mathrm{v}$ trypsin. Neurons were centrifuged $(1000 \times g$ for $5 \mathrm{~min})$ and resuspended in neurobasal medium containing $2 \%$ B27 serum-free supplement, $1 \% \mathrm{v} / \mathrm{v}$ penicillin/streptomycin $(\mathrm{P} / \mathrm{S}), 0.5$ $\mathrm{mM}$ glutamine, and $10 \mu \mathrm{M}$ glutamate. Dissociated cells were then plated with appropriate densities in culture plates or dishes pre-coated with PDL. Cultures were kept at $37^{\circ} \mathrm{C}$ in a $5 \% \mathrm{v} / \mathrm{v} \mathrm{CO}$ humidified incubator. Thereafter, one third to half of the medium was replaced twice a week (see details in Supplementary Methods).

Individually inhabited hippocampal neurons were grown on collagen-PDL islands. Briefly, $6.5 \mathrm{~mm}$ Transwell ${ }^{\oplus}$ inserts in 24 well plates were coated with PDL ( $12 \mathrm{~h}$ before culture), and coverslips were sprayed with island substrate solution containing $1 \mathrm{mg} \mathrm{ml}^{-1} \mathrm{PDL}$ and $3 \mathrm{mg} \mathrm{ml}^{-1}$ rat tail collagen ( $3 \mathrm{~h}$ before culture). Dissociated cells were then plated at a density of 2000 cells per $\mathrm{cm}^{2}$ onto coverslips in 24-well plates (for micro-island culture) or at a density of 50,000 cells per $\mathrm{cm}^{2}$ in Transwell ${ }^{\circledR}$ inserts in 24-well plates (as high density neuronal feeder layer). After an adherence time of $4 \mathrm{~h}$, the transwell inserts with neurons (high density) were placed into 24-well plates with neurons on coverslips (low density). Procedures for maintaining cultured islands were similar to those for primary hippocampal neuron cultures (see details in Supplementary Methods).

Astrocyte cultures were prepared from 0 to 1-day-old (P0-1) mice ${ }^{69}$. Cortices were dissected from 0 to 1 -day-old mice and digested with $0.25 \% \mathrm{w} / \mathrm{v}$ trypsin in DMEM. Cells were allowed to grow for at least 7 days at $37^{\circ} \mathrm{C}$ with $5 \% \mathrm{CO}_{2}$, and a complete medium change was performed every other day. At confluence after DIV8-10, cultures were shaken, and then incubated with $20 \mu \mathrm{M}$ cytosine-1- $\beta-\mathrm{D}$ arabinofuranosid (see details in Supplementary Methods).

FM1-43 loading and synaptic vesicle detection. Cultured neurons (DIV14) were transferred into a standard bath solution with $10 \mu \mathrm{M}$ DNQX and $40 \mu \mathrm{M}$ D-AP5. Neurons were then incubated with $5 \mu \mathrm{M}$ FM1-43 in a hyperkalemic bath solution for $90 \mathrm{~s}$. FM1-43 was then washout followed by adding ADVASEP-7 to reduce background fluorescence. Images were taken by a confocal laser-scanning microscope (Nikon A1). FM1-43-loaded vesicles were viewed through a 40X oilimmersion objective and images were acquired at a resolution of $1024 \times 1024$ pixel at RT (see details in Supplementary Methods).

Western blotting. Hippocampi were obtained and homogenized using a chilled Vibrahomogenizer (Vibra cell, SONICS) in $2 \mathrm{ml}$ of RIPA buffer. The lysate was then centrifuged, and the supernatant collected for Western blot analysis. Proteins were separated on SDS-PAGE under denaturing conditions (for Efr3a, 10-15\% Mini-PROTEAN TGX Gels; for A $\beta$ and CTFs, $16.5 \%$ Tris-Tricine Gels) and transferred to polyvinylidene fluoride (PVDF) microporous membrane (Millipore). The membranes were then blocked with 5\% skim milk-TBS (for A $\beta$ ) or $0.35 \%$ gelatin-TBST (for other proteins), and incubated with the primary antibodies followed by HRP-conjugated secondary antibodies. Protein bands were then visualized using the ECL western blotting detection substrate and analyzed with ImageJ software. Detailed protocols are available in Supplementary Methods.

Cultured neuron recording. Single-cell micro-island neuron cultures at DIV14 were used for recording. Neurons were voltage clamped at $-70 \mathrm{mV}$ with a Heka EPC 10 amplifier and mEACs were recorded at $32^{\circ} \mathrm{C}$ in bath solution containing $0.5 \mu \mathrm{M}$ TTX and $10 \mu \mathrm{M}$ bicuculline. Individual events were counted and analyzed with MiniAnalysis software (see details in Supplementary Methods).

Lipid strip assay. PIP Strips ${ }^{\mathrm{TM}}$ membranes were used for the anti-PIP ${ }_{2}$ antibody specificity measurement according to the manufacturer's instructions. Detailed protocols are available in Supplementary Methods.

ELISA PIP $\mathbf{2}_{\mathbf{2}}$ assay. Mass ELISA Kit K-4500 from Echelon Biosciences was used to determine PIP ${ }_{2}$ levels in hippocampi from WT and APP/PS1 mice (6-7-monthold), and in primary cultured hippocampal neurons from WT and $E f r 3 a^{+/-}$mice according to the manufacturer's instructions ${ }^{55}$. Detailed protocols are available in Supplementary Methods.

Immunocytochemistry. Immunofluorescence staining was carried out in cultured neurons at DIV $14^{69}$. Briefly, neurons were fixed and permeabilized followed by incubation with primary antibodies and the appropriate secondary antibodies. For co-staining with mGluR5, neurons were permeabilized before the secondary blocking, and the primary antibodies were used. Fluorescent images were acquired through a $60 \mathrm{X}$ oil-immersion objective using a Nikon A1 confocal laser-scanning microscope. Neuronal images were analyzed using MetaMorph with customized filter sets. Detailed protocols are available in Supplementary Methods.

Lentivirus-shRNA infection. Cultured hippocampal neurons at DIV7 were infected with lentivirus carrying DsRed-PLC $\beta 1$-shRNA (PLC $\beta 1$-shRNA) or DsRed-PLC $\beta 4$-shRNA (PLC $\beta 4$-shRNA) to knock down PLC $\beta 1$ or PLC $\beta 4$. Lentivirus expressing DsRed-scramble-shRNA was used as control. Neurons were then treated with $\mathrm{A} \beta$ or DMSO, and subsequently used for Western blotting (interference efficiency detection) or immunofluorescence staining. Detailed protocols are available in Supplementary Methods.

$\mathbf{C a}^{2+}$ imaging. Changes in $\left[\mathrm{Ca}^{2+}\right]_{\mathrm{i}}$ were measured in astrocytes (WT and $E f r 3 a$ ${ }^{+-}$) using the calcium-sensitive fluorescent dye Fluo-4. The astrocytes were washed with Krebs buffer and incubated with $4 \mu \mathrm{M}$ Fluo- 4 in Krebs buffer. Fluo- 4 loaded astrocytes were excited at $488 \mathrm{~nm}$ and fluorescence emission was detected at $525 \mathrm{~nm}$. The images [(baseline data $\left(F_{0}\right)$ and treated data $\left.(F)\right]$ were taken through a $60 \mathrm{X}$ oil-immersion objective by a Nikon A1 confocal laser-scanning microscope. The relative Fluo-4 fluorescent signals expressed in arbitrary units $\left(F / F_{0}\right)$ were analyzed for individual cells using MetaMorph with a fixed set of parameters (see details in Supplementary Methods).

MWM test. The MWM tests were performed in a circular tank filled with opaque water at $25^{\circ} \mathrm{C}$. Twenty-four hours before the acquisition test, a visible platform task was tested in each quadrant of the tank. In the hidden platform acquisition test, mice could swim freely to search for the escape platform within $60 \mathrm{~s}$. The time taken to reach the platform was recorded as the escape latency. Mice were allowed to stay on the platform for $10 \mathrm{~s}$ after the hidden platform was found. The same animal was then released from a new insertion point $4 \mathrm{~min}$ after the previous trial. The experiment was repeated four times per mouse each day for 5 days. Twentyfour hours after the hidden platform acquisition test, probe trials were conducted by removing the platform. The numbers of entries into the area where the original platform was located and crossings over the original platform were recorded. The data were analyzed by the WaterMaze Software (Actimetrics, INC.). Detailed protocols are available in Supplementary Methods.

Statistics and reproducibility. GraphPad Prism (Version 5.01, Graph-Pad Software Inc.) was used for data display and statistical analysis. We did not predetermine sample sizes. We used Kolmogorov-Smirnov normality test to determine most data are Gaussian distributed. Significance is reported as $P<0.05$, and data were expressed as mean \pm SEM. Two-tailed Student $t$ test, one-way ANOVA followed by a post hoc multiple comparison analysis based on the Dunnett's Method, two-way ANOVA followed by a post hoc Bonferroni test, or two-way RM ANOVA followed by a post hoc Bonferroni test were used to determine significant levels between treatments and controls. Distributions of mEPSC amplitudes and interevent intervals were compared using KolmogorovSmirnov test. 


\section{Data availability}

All data generated or analyzed during this study are included in this published article and its supplementary information files. The source data underlying Figs. 1-10 and Supplementary Figs 1-15 are provided as two Source Data files.

Received: 12 March 2018 Accepted: 21 February 2019

Published online: 13 March 2019

\section{References}

1. Ballard, C. et al. Alzheimer's disease. Lancet 377, 1019-1031 (2011).

2. Hardy, J. \& Selkoe, D. J. The amyloid hypothesis of Alzheimer's disease: progress and problems on the road to therapeutics. Science 297, 353-356 (2002).

3. Polanco, J. C. et al. Amyloid-beta and tau complexity-towards improved biomarkers and targeted therapies. Nat. Rev. Neurol. 14, 22-39 (2018).

4. Selkoe, D. J. Alzheimer's disease is a synaptic failure. Science 298, 789-791 (2002)

5. Terry, R. D. et al. Physical basis of cognitive alterations in Alzheimer's disease: synapse loss is the major correlate of cognitive impairment. Ann. Neurol. $\mathbf{3 0}$ 572-580 (1991).

6. Herms, J. \& Dorostkar, M. M. Dendritic Spine Pathology in Neurodegenerative Diseases. Annu. Rev. Pathol. 11, 221-250 (2016).

7. Canter, R. G., Penney, J. \& Tsai, L. H. The road to restoring neural circuits for the treatment of Alzheimer's disease. Nature 539, 187-196 (2016).

8. Palop, J. J. \& Mucke, L. Amyloid-beta-induced neuronal dysfunction in Alzheimer's disease: from synapses toward neural networks. Nat. Neurosci. 13, 812-818 (2010).

9. Benilova, I., Karran, E. \& De Strooper, B. The toxic Abeta oligomer and Alzheimer's disease: an emperor in need of clothes. Nat. Neurosci. 15, 349-357 (2012).

10. De Strooper, B. \& Karran, E. The Cellular Phase of Alzheimer's disease. Cell 164, 603-615 (2016)

11. Forner, S., Baglietto-Vargas, D., Martini, A. C., Trujillo-Estrada, L. \& LaFerla, F. M. Synaptic impairment in Alzheimer's disease: a dysregulated symphony. Trends Neurosci. 40, 347-357 (2017).

12. Koffie, R. M. et al. Oligomeric amyloid beta associates with postsynaptic densities and correlates with excitatory synapse loss near senile plaques. Proc. Natl Acad. Sci. USA 106, 4012-4017 (2009).

13. Pickett, E. K. et al. Non-fibrillar oligomeric amyloid-beta within synapses. J. Alzheimers Dis. 53, 787-800 (2016).

14. Fu, A. K. \& Ip, N. Y. Regulation of postsynaptic signaling in structural synaptic plasticity. Curr. Opin. Neurobiol. 45, 148-155 (2017).

15. Sheng, M., Sabatini, B.L. \& Sudhof, T.C. Synapses and Alzheimer's disease. Cold Spring Harb. Perspect. Biol. 4, a005777 (2012).

16. Parodi, J. et al. Beta-amyloid causes depletion of synaptic vesicles leading to neurotransmission failure. J. Biol. Chem. 285, 2506-2514 (2010).

17. Ting, J. T., Kelley, B. G., Lambert, T. J., Cook, D. G. \& Sullivan, J. M. Amyloid precursor protein overexpression depresses excitatory transmission through both presynaptic and postsynaptic mechanisms. Proc. Natl Acad. Sci. USA 104, 353-358 (2007)

18. Cirrito, J. R. et al. In vivo assessment of brain interstitial fluid with microdialysis reveals plaque-associated changes in amyloid-beta metabolism and half-life. J. Neurosci. 23, 8844-8853 (2003)

19. Abramov, E. et al. Amyloid-beta as a positive endogenous regulator of release probability at hippocampal synapses. Nat. Neurosci. 12, 1567-1576 (2009).

20. Fogel, H. et al. APP homodimers transduce an amyloid-beta-mediated increase in release probability at excitatory synapses. Cell Rep. 7, 1560-1576 (2014).

21. Bobich, J. A., Zheng, Q. \& Campbell, A. Incubation of nerve endings with a physiological concentration of Abeta1-42 activates CaV2.2(N-Type)-voltage operated calcium channels and acutely increases glutamate and noradrenaline release. J. Alzheimers Dis. 6, 243-255 (2004).

22. Lazarevic, V. et al. Physiological concentrations of amyloid beta regulate recycling of synaptic vesicles via alpha7 acetylcholine receptor and CDK5/ calcineurin signaling. Front. Mol. Neurosci. 10, 221 (2017).

23. Puzzo, D. et al. Picomolar amyloid-beta positively modulates synaptic plasticity and memory in hippocampus. J. Neurosci. 28, 14537-14545 (2008).

24. Moreno, H. et al. Synaptic transmission block by presynaptic injection of oligomeric amyloid beta. Proc. Natl Acad. Sci. USA 106, 5901-5906 (2009).

25. Nimmrich, V. et al. Amyloid beta oligomers (A beta(1-42) globulomer) suppress spontaneous synaptic activity by inhibition of P/Q-type calcium currents. J. Neurosci. 28, 788-797 (2008).

26. Yang, Y. et al. Amyloid-beta oligomers may impair SNARE-mediated exocytosis by direct binding to syntaxin 1a. Cell Rep. 12, 1244-1251 (2015).
27. Hermann, D. et al. Synthetic Abeta oligomers (Abeta(1-42) globulomer) modulate presynaptic calcium currents: prevention of Abeta-induced synaptic deficits by calcium channel blockers. Eur. J. Pharmacol. 702, 44-55 (2013).

28. Russell, C. L. et al. Amyloid-beta acts as a regulator of neurotransmitter release disrupting the interaction between synaptophysin and VAMP2. PLOS ONE 7, e43201 (2012)

29. Li, S. et al. Soluble oligomers of amyloid Beta protein facilitate hippocampal long-term depression by disrupting neuronal glutamate uptake. Neuron $\mathbf{6 2}$, 788-801 (2009).

30. Shankar, G. M. et al. Amyloid-beta protein dimers isolated directly from Alzheimer's brains impair synaptic plasticity and memory. Nat. Med. 14, 837-842 (2008).

31. Mezler, M., Barghorn, S., Schoemaker, H., Gross, G. \& Nimmrich, V. A betaamyloid oligomer directly modulates $\mathrm{P} / \mathrm{Q}$-type calcium currents in Xenopus oocytes. Br. J. Pharmacol. 165, 1572-1583 (2012).

32. $\mathrm{Hu}, \mathrm{N}$. W. et al. mGlu5 receptors and cellular prion protein mediate amyloidbeta-facilitated synaptic long-term depression in vivo. Nat. Commun. 5, 3374 (2014).

33. Renner, M. et al. Deleterious effects of amyloid beta oligomers acting as an extracellular scaffold for mGluR5. Neuron 66, 739-754 (2010).

34. Um, J. W. et al. Metabotropic glutamate receptor 5 is a coreceptor for Alzheimer abeta oligomer bound to cellular prion protein. Neuron 79, 887-902 (2013).

35. Haas, L. T. et al. Silent allosteric modulation of mGluR5 maintains glutamate signaling while rescuing Alzheimer's mouse phenotypes. Cell Rep. 20, 76-88 (2017).

36. Hamilton, A., Esseltine, J. L., DeVries, R. A., Cregan, S. P. \& Ferguson, S. S Metabotropic glutamate receptor 5 knockout reduces cognitive impairment and pathogenesis in a mouse model of Alzheimer's disease. Mol. Brain 7, 40 (2014).

37. Hamilton, A. et al. Chronic pharmacological mGluR5 inhibition prevents cognitive impairment and reduces pathogenesis in an Alzheimer disease mouse model. Cell Rep. 15, 1859-1865 (2016).

38. Berman, D. E. et al. Oligomeric amyloid-beta peptide disrupts phosphatidylinositol-4,5-bisphosphate metabolism. Nat. Neurosci. 11, 547-554 (2008).

39. Zhu, L. et al. Phospholipid dysregulation contributes to ApoE4-associated cognitive deficits in Alzheimer's disease pathogenesis. Proc. Natl Acad. Sci. USA 112, 11965-11970 (2015).

40. McIntire, L. B. et al. Reduction of synaptojanin 1 ameliorates synaptic and behavioral impairments in a mouse model of Alzheimer's disease. J. Neurosci. 32, 15271-15276 (2012).

41. Merino-Serrais, P., Knafo, S., Alonso-Nanclares, L., Fernaud-Espinosa, I. \& DeFelipe, J. Layer-specific alterations to CA1 dendritic spines in a mouse model of Alzheimer's disease. Hippocampus 21, 1037-1044 (2011).

42. Park, J., Jang, M. \& Chang, S. Deleterious effects of soluble amyloid-beta oligomers on multiple steps of synaptic vesicle trafficking. Neurobiol. Dis. 55, 129-139 (2013)

43. Woo, J. A. et al. RanBP9 at the intersection between cofilin and Abeta pathologies: rescue of neurodegenerative changes by RanBP9 reduction. Cell Death Dis. 6, 1676 (2015).

44. Harris, J. A. et al. Transsynaptic progression of amyloid-beta-induced neuronal dysfunction within the entorhinal-hippocampal network. Neuron 68 428-441 (2010).

45. Garcia-Alloza, M. et al. Existing plaques and neuritic abnormalities in APP: PS1 mice are not affected by administration of the gamma-secretase inhibitor LY-411575. Mol. Neurodegener. 4, 19 (2009).

46. Lee, H. K. et al. Dynamic Ca2+-dependent stimulation of vesicle fusion by membrane-anchored synaptotagmin 1. Science 328, 760-763 (2010).

47. Falkenburger, B. H., Jensen, J. B., Dickson, E. J., Suh, B. C. \& Hille, B. Phosphoinositides: lipid regulators of membrane proteins. J. Physiol. 588, 3179-3185 (2010)

48. Bojjireddy, N., Guzman-Hernandez, M. L., Reinhard, N. R., Jovic, M. \& Balla, T. EFR3s are palmitoylated plasma membrane proteins that control responsiveness to G-protein-coupled receptors. J. Cell Sci. 128, 118-128 (2015).

49. Gelman, S., Palma, J., Tombaugh, G. \& Ghavami, A. Differences in synaptic dysfunction between rTg4510 and APP/PS1 mouse models of Alzheimer's disease. J. Alzheimers Dis. 61, 195-208 (2018).

50. Cummings, D. M. et al. First effects of rising amyloid-beta in transgenic mouse brain: synaptic transmission and gene expression. Brain 138, 1992-2004 (2015)

51. Whitcomb, D. J. et al. Intracellular oligomeric amyloid-beta rapidly regulates GluA1 subunit of AMPA receptor in the hippocampus. Sci. Rep. 5, 10934 (2015).

52. Viana da Silva, S. et al. Early synaptic deficits in the APP/PS1 mouse model of Alzheimer's disease involve neuronal adenosine A2A receptors. Nat. Commun. 7, 11915 (2016). 
53. Zhang, C. et al. Presenilins are essential for regulating neurotransmitter release. Nature 460, 632-636 (2009).

54. Di Paolo, G. \& Kim, T. W. Linking lipids to Alzheimer's disease: cholesterol and beyond. Nat. Rev. Neurosci. 12, 284-296 (2011).

55. Trovo, L. et al. Low hippocampal $\mathrm{PI}(4,5) \mathrm{P}(2)$ contributes to reduced cognition in old mice as a result of loss of MARCKS. Nat. Neurosci. 16, 449-455 (2013).

56. Walter, A.M. et al. Phosphatidylinositol 4,5-bisphosphate optical uncaging potentiates exocytosis. Elife 6, e30203 (2017).

57. Romano, C. et al. Distribution of metabotropic glutamate receptor mGluR5 immunoreactivity in rat brain. J. Comp. Neurol. 355, 455-469 (1995).

58. Hsieh, H. et al. AMPAR removal underlies Abeta-induced synaptic depression and dendritic spine loss. Neuron 52, 831-843 (2006).

59. Snyder, E. M. et al. Regulation of NMDA receptor trafficking by amyloid-beta. Nat. Neurosci. 8, 1051-1058 (2005)

60. Zhang, $\mathrm{H}$. et al. Neuronal store-operated calcium entry and mushroom spine loss in amyloid precursor protein knock-in mouse model of Alzheimer's disease. J. Neurosci. 35, 13275-13286 (2015).

61. Bayazitov, I. T., Richardson, R. J., Fricke, R. G. \& Zakharenko, S. S. Slow presynaptic and fast postsynaptic components of compound long-term potentiation. J. Neurosci. 27, 11510-11521 (2007).

62. Zakharenko, S. S., Zablow, L. \& Siegelbaum, S. A. Visualization of changes in presynaptic function during long-term synaptic plasticity. Nat. Neurosci. 4, 711-717 (2001).

63. Emptage, N. J., Reid, C. A., Fine, A. \& Bliss, T. V. Optical quantal analysis reveals a presynaptic component of LTP at hippocampal Schafferassociational synapses. Neuron 38, 797-804 (2003).

64. Enoki, R., Hu, Y. L., Hamilton, D. \& Fine, A. Expression of long-term plasticity at individual synapses in hippocampus is graded, bidirectional, and mainly presynaptic: optical quantal analysis. Neuron 62, 242-253 (2009).

65. Nakatsu, F. et al. PtdIns4P synthesis by PI4KIIIalpha at the plasma membrane and its impact on plasma membrane identity. J. Cell Biol. 199, 1003-1016 (2012).

66. $\mathrm{Wu}, \mathrm{X}$. et al. Structural insights into assembly and regulation of the plasma membrane phosphatidylinositol 4-kinase complex. Dev. Cell 28, 19-29 (2014).

67. Di Paolo, G. et al. Impaired PtdIns(4,5)P2 synthesis in nerve terminals produces defects in synaptic vesicle trafficking. Nature 431, 415-422 (2004).

68. Zhang, X. et al. Downregulation of RBO-PI4KIIIalpha facilitates Abeta42 secretion and ameliorates neural deficits in Abeta42-expressing Drosophila. J. Neurosci. 37, 4928-4941 (2017).

69. Shen, Y. et al. Postnatal activation of TLR4 in astrocytes promotes excitatory synaptogenesis in hippocampal neurons. J. Cell Biol. 215, 719-734 (2016).

70. Zhou, Y. D. et al. Arrested maturation of excitatory synapses in autosomal dominant lateral temporal lobe epilepsy. Nat. Med. 15, 1208-1214 (2009).

\section{Acknowledgements}

This work was supported by the Major Research Program from the State Ministry of Science and Technology of China (2013CB530902), the National Natural Science Foundation of China grants $(81770839,81571125,81571088,91132712,81300979$,
81821091, 81521062, and 81221003), the 111 project, and the Non-profit Central Research Institute Fund of Chinese Academy of Medical Sciences (2017PT31038 and 2018PT31041). We thank the excellent technical assistant of the Imaging Facility at Zhejiang University School of Medicine.

\section{Author contributions}

Y.-D.Z., Yi S. and F.-D.H. designed the study. Y.-D.Z., Yi S., Y.H. and M.W. wrote the paper. Yi S., Y.H., M.W., Y.W., X.M. and W.L. analyzed the data. Y.H. and X.M. performed electrophysiology experiments. Y.H. performed synaptic vesicle detection and $\mathrm{Ca}^{2+}$ imaging experiments. M.W. and Y.W. did behavioral studies. M.W., H.Q., Y.W., J.C. and W.L. did immunostaining and biochemical studies. F.-D.H. engineered Efr3a transgenic mice. B.S., J.R., Z.C. and Ye S. contributed intellectually to the manuscript.

\section{Additional information}

Supplementary Information accompanies this paper at https://doi.org/10.1038/s41467 019-09114-z.

Competing interests: F.-D.H. has shareholding of a company possessing part of the intellectual property raised in this study. The remaining authors declare no competing interests.

Reprints and permission information is available online at http://npg.nature.com/ reprintsandpermissions/

Journal Peer Review Information: Nature Communications thanks the anonymous reviewer(s) for their contribution to the peer review of this work. Peer reviewer reports are available.

Publisher's note: Springer Nature remains neutral with regard to jurisdictional claims in published maps and institutional affiliations.

Open Access This article is licensed under a Creative Commons Attribution 4.0 International License, which permits use, sharing, adaptation, distribution and reproduction in any medium or format, as long as you give appropriate credit to the original author(s) and the source, provide a link to the Creative Commons license, and indicate if changes were made. The images or other third party material in this article are included in the article's Creative Commons license, unless indicated otherwise in a credit line to the material. If material is not included in the article's Creative Commons license and your intended use is not permitted by statutory regulation or exceeds the permitted use, you will need to obtain permission directly from the copyright holder. To view a copy of this license, visit http://creativecommons.org/ licenses/by/4.0/

(c) The Author(s) 2019 